\title{
Capture of activated dioxygen intermediates at the copper-active site of a lytic polysaccharide monooxygenase
}

\author{
Gabriela C. Schröder ${ }^{1,2}$, William B. O’Dell ${ }^{1,2,3}$, Simon P. Webb ${ }^{4}$, Pratul K. Agarwal ${ }^{5 *}$ and Flora Meilleur ${ }^{1,2 *}$ \\ ${ }^{1}$ Department of Molecular and Structural Biochemistry, North Carolina State University, Raleigh, NC \\ 27695, USA \\ ${ }^{2}$ Neutron Scattering Division, Oak Ridge National Laboratory, Oak Ridge, TN 37831, USA \\ ${ }^{3}$ Current affiliations: Biomolecular Measurement Division, National Institute of Standards and Technology, \\ Gaithersburg, MD 20899; Biomolecular Labeling Laboratory, Institute for Bioscience and Biotechnology \\ Research, Rockville, MD 20850 \\ ${ }^{4}$ VeraChem LLC, 12850 Middlebrook Rd. Ste 205, Germantown, MD 20874-5244, USA \\ ${ }^{5}$ Department of Physiological Sciences and High-Performance Computing Center, Oklahoma State \\ University, Stillwater, OK 74078, USA
}

\begin{abstract}
Metalloproteins perform a diverse array of redox-related reactions facilitated by the increased chemical functionality afforded by their metallocofactors. Lytic polysaccharide monooxygenases (LPMOs) are a class of copper-dependent enzymes that are responsible for the breakdown of recalcitrant polysaccharides via oxidative cleavage at the glycosidic bond. The activated copper-oxygen intermediates and their mechanism of formation remains to be established. Neutron protein crystallography which permits direct visualization of protonation states was used to investigate the initial steps of oxygen activation directly following active site copper reduction in Neurospora crassa LPMO9D. Herein, we cryotrap an activated dioxygen intermediate in a mixture of superoxo and hydroperoxo states, and we identify the conserved second coordination shell residue His157 as the proton donor. Density functional theory (DFT) calculations indicate that both active site states are stable. The hydroperoxo formed is potentially an intermediate in the mechanism of hydrogen peroxide formation in the absence of substrate. We establish that the $\mathrm{N}$-terminal amino group of the copper coordinating His1 remains doubly protonated directly following molecular oxygen reduction by copper. Aided by mining minima free energy calculations we establish His157 conformational flexibility in solution that is abolished by steric hindrance in the
\end{abstract}


crystal. A neutron crystal structure of NcLPMO9D at low pH supports occlusion of the active site which prevents protonation of His157 at acidic conditions.

\section{Introduction}

Lytic polysaccharide monooxygenases (LPMOs; also designated PMOs) are copper metalloenzymes that perform unique redox chemistry resulting in disruption of polysaccharide chains by oxygen atom insertion at the glycosidic bond. ${ }^{1}$ The LPMO active site contains a mononuclear $\mathrm{Cu}^{2+}$ center within a "histidine brace" motif in which the copper is coordinated by the N-terminal histidine amino group, the $\mathrm{N}_{\delta}$ atom of His1 and the $\mathrm{N}_{\varepsilon}$ atom of a second conserved histidine. ${ }^{2}$ Of particular commercial and biotechnological interest is the ability of fungal LPMOs to catalyze the oxidative cleavage of recalcitrant crystalline cellulose at the $\mathrm{C} 1$ and/or $\mathrm{C} 4$ position, thereby enhancing polysaccharide depolymerization by increasing glucan access to hydrolytic enzymes via the overall reaction shown in Scheme $1 .^{3-5}$
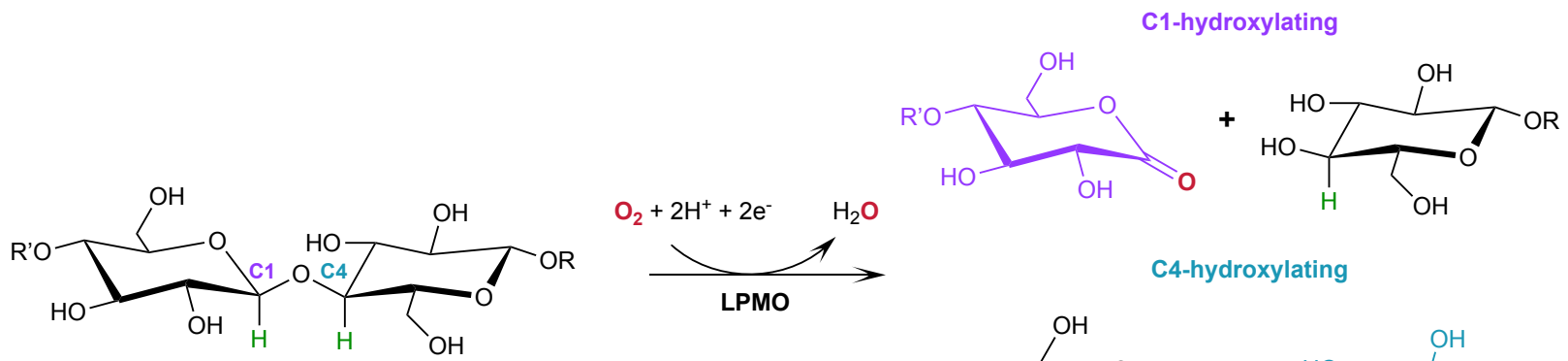

C4-hydroxylating

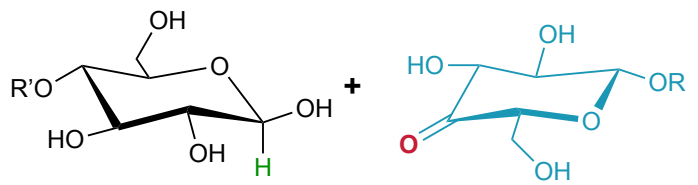

Scheme 1 Oxidation of the C1/C4 carbon in the glycosidic bond catalyzed by LPMOs with oxygen as the co-substrate. $\mathrm{H}$ atoms to be abstracted by the reactive oxygen species shown in green.

While $\mathrm{H}_{2} \mathrm{O}_{2}$ has also been shown to be a LPMO co-substrate, ${ }^{6}$ the work presented here focuses on the activation of $\mathrm{O}_{2}$, the first characterized co-substrate in polysaccharide oxidation and the substrate in the synthesis of $\mathrm{H}_{2} \mathrm{O}_{2}$ in absence of substrate. ${ }^{3-5}$ One-electron reduction of the copper active site to $\mathrm{Cu}^{1+}$ and binding of the molecular oxygen co-substrate initiates the reaction cycle with the generally accepted 
formation of a $\mathrm{Cu}^{2+}$ superoxide, $\left[\mathrm{Cu}-\mathrm{O}_{2}\right]^{+}{ }^{3,4,7,8}$ In the current consensus for the $\mathrm{O}_{2}$-based mechanism, following the rapid reduction of molecular dioxygen to the superoxide, the LPMO reaction mechanism requires further delivery of electrons and protons to form a reactive oxygen intermediate which oxidizes the polysaccharide substrate. ${ }^{9}$ The identity of the activated oxygen species responsible for hydrogen atom abstraction (HAA) from the polysaccharide substrate leading to subsequent substrate oxidation, is however still a matter of ongoing research. ${ }^{10}$ Intensive studies encompassing X-ray crystallographic, computational and spectroscopic examinations of mononuclear copper monooxygenases as well as biomimetic copper complexes have proposed dioxygen intermediates such as the superoxide $\left[\mathrm{Cu}-\mathrm{O}_{2}\right]^{+}$and hydroperoxo $[\mathrm{CuOOH}]^{+}$species where the $\mathrm{O}-\mathrm{O}$ bond remains intact. ${ }^{8,11-14}$ Furthermore, formation of the hydroxide $[\mathrm{CuOH}]^{2+}$ and oxyl $[\mathrm{CuO}]^{+}$intermediates after $\mathrm{O}-\mathrm{O}$ bond scission, with subsequent involvement in HAA, have been proposed. ${ }^{15-23}$ Formation of a hydroperoxo, hydroxy or oxyl HAA species would require further protonation and reduction of the superoxide however the identity of the proton donor is still debated. Several second-shell residues including histidine (His147 in LsLPMO9A/His 161 in MtPMO3*) as well as glutamine (GIn167 in MtPMO3* and glutamate (Glu201 in JdLPMO10A) have been proposed to be involved in intermediate protonation. ${ }^{22,24,25}$ Quantum mechanics/molecular mechanics (QM/MM) calculations have also shown that a hydrogen atom could be abstracted by the superoxide species from an exogenous reducing agent such as ascorbic acid. ${ }^{26}$

Neutron protein crystallography is particularly well suited to the determination of protonation states within a protein due to the technique's unique sensitivity to hydrogen atoms and protons often invisible to X-ray diffraction. ${ }^{27,28}$ Neutron protein crystallography is also a non-destructive technique ideally suited for the study of radiation-sensitive metalloproteins. ${ }^{29}$ We report here two neutron models of a carbohydrate-free C4-hydroxylating Neurospora crassa LPMO9D: a structure of the activated, ascorbate-reduced form and a structure of the resting state at $\mathrm{pH} 4.4$ (pD 4.8) to further address open 
questions regarding initial molecular oxygen activation. The neutron crystallographic structure of the reduced NCLPMO9D shows cryo-capture of activated dioxygen at the copper active site modelled as a superoxo and protonated hydroperoxo species with a population ratio of $0.30: 0.70$. The neutron scattering length density maps of the conserved secondary coordination shell His157 is best represented as $70 \%$ imidazolate and a $30 \%$ singly protonated form. The copper coordinating $\mathrm{N}$-terminal amino group His1 remains in a doubly protonated $\mathrm{ND}_{2}$ state following copper reduction and molecular oxygen activation. Mining minima energy calculations reveal His157 flexibility in solution which is absent in the crystal structure due to binding-face to binding-face crystal packing. Furthermore, the neutron and X-ray crystal structures of the resting state NCLPMO9D at low pH show that His157 remains singly protonated when exposed to acidic conditions.

\section{Results and discussion}

\section{Crystallographic features of the NcLPMO9D neutron structures}

Both the ascorbate-reduced and low pH neutron crystals of NcLPMO9D belonged to the monoclinic $P 2_{1}$ space group. The crystal structures include two protein molecules per asymmetric unit (Molecule A and Molecule B) related by non-crystallographic symmetry (NCS). Analysis of the crystallographic contacts shows that the two NCS related NCLPMO9D molecules pack with their planar polysaccharide binding interfaces against each other in a binding-face to binding-face configuration also seen in PDB structures 4EIR, 5TKG, 5TKH and 5TKI (Fig. 1A). ${ }^{7,30,31}$ While present in a dimeric conformation in the crystal structure, LPMOs including NcLPMO9D function as single-domain monomeric proteins in solution, where they associate with planar crystalline cellulose as confirmed by early LPMO structural studies, $^{7,32,33}$ and single-molecule observations of LPMO using atomic force microscopy (AFM). ${ }^{34}$ Within this binding-face to binding-face packing architecture, the two coordinated coppers are $\sim 12 \AA$ apart, precluding direct interaction. Binding interface residues Tyr25, Tyr206 and Trp207 adopt distinct conformations in Molecule $\mathrm{A}$ and $\mathrm{B}$, contributing to different microenvironments near the $\mathrm{Cu}^{2+}$ active site 
(Fig. 1B). Structural alignment of our NcLPMO9D Molecule A or Molecule B with the oligosaccharidebound form of $L S L P M O 9 A$ (PDB $5 A C l$ ), ${ }^{35}$ indicates that the substrate pyranose rings of the $L S L P M O 9 A$ structure superimpose with the proline rings Pro43 and Pro163 for both Molecule A or Molecule B of NcLPMO9D (Fig. 1C). The alignment further indicates that Tyr206 of Molecule A is positioned to interact with substrate via its phenol ring. This suggests that the crystallographic environment of the active site in Molecule A more closely mimics surface residue interaction with the pyranose ring of the glucose units and creates an occluded active site, possibly analogous to the bulk solvent-protected environment created when the planar active site of LPMO binds to its crystalline linear polysaccharide substrate. Such crystal packing in which active site residues mimic carbohydrate substrate pyranose rings has also been observed in the crystal packing of NCLPMO-3 (PDB 4EIS). ${ }^{7}$ Representation of the protein surface additionally illustrates the active site occlusion due to crystal packing (Fig. 2). 

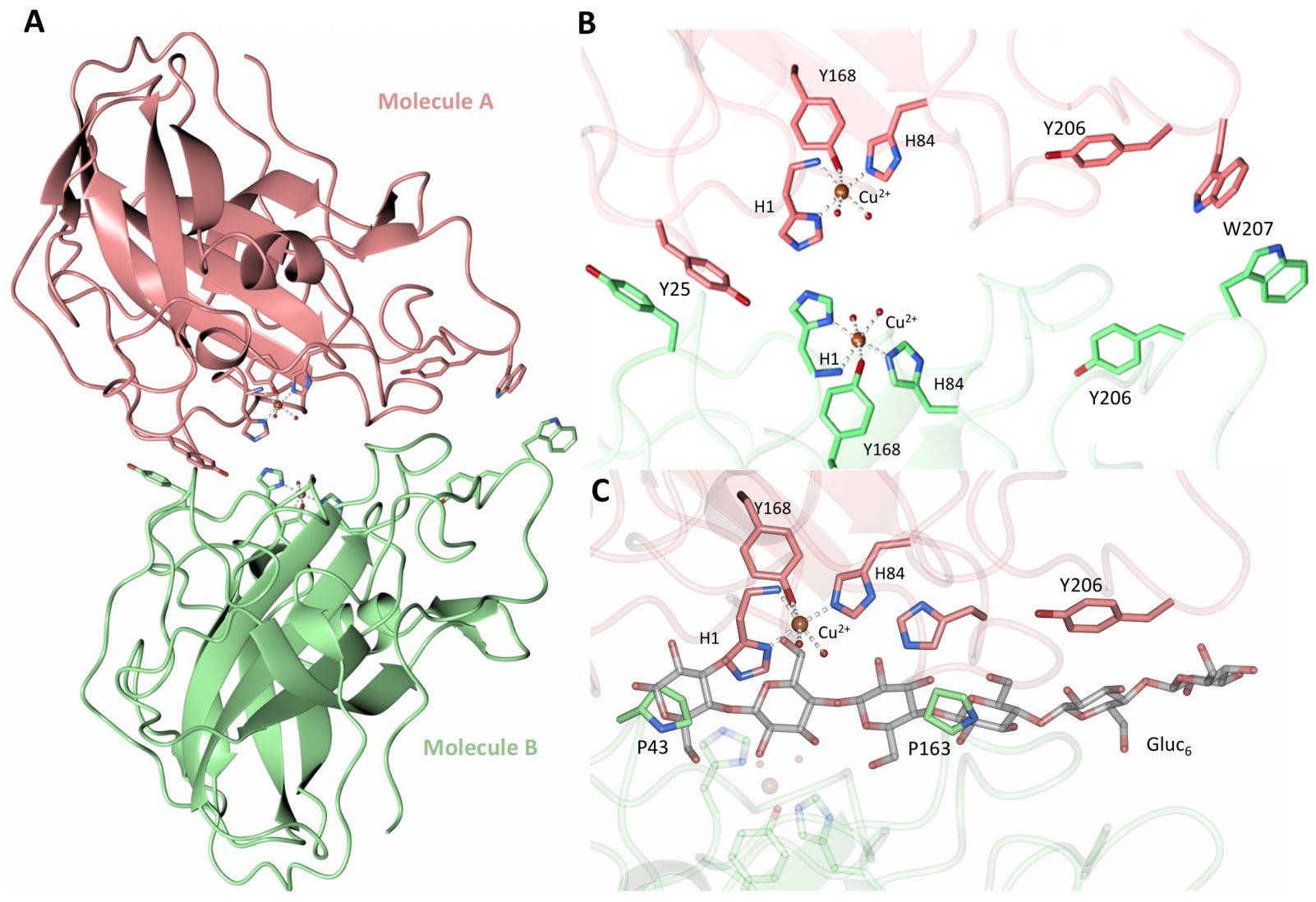

Figure 1 Crystal packing of the Molecule A and B in the LPMO9D crystals. (A) Cartoon of Molecule A (coral) and Molecule B (light green) of the planar active site surfaces packed facing each other. (B) Crystal symmetry in Molecule A and B is broken by alternate conformations of Tyr 25, Tyr206 and Trp207. (C) Alignment of Molecule B of NcLPMO9D with the Gluc bound LsLPMO9A (PDB 5ACI) in grey to illustrate superposition of proline residues with glucose pyranose rings. 

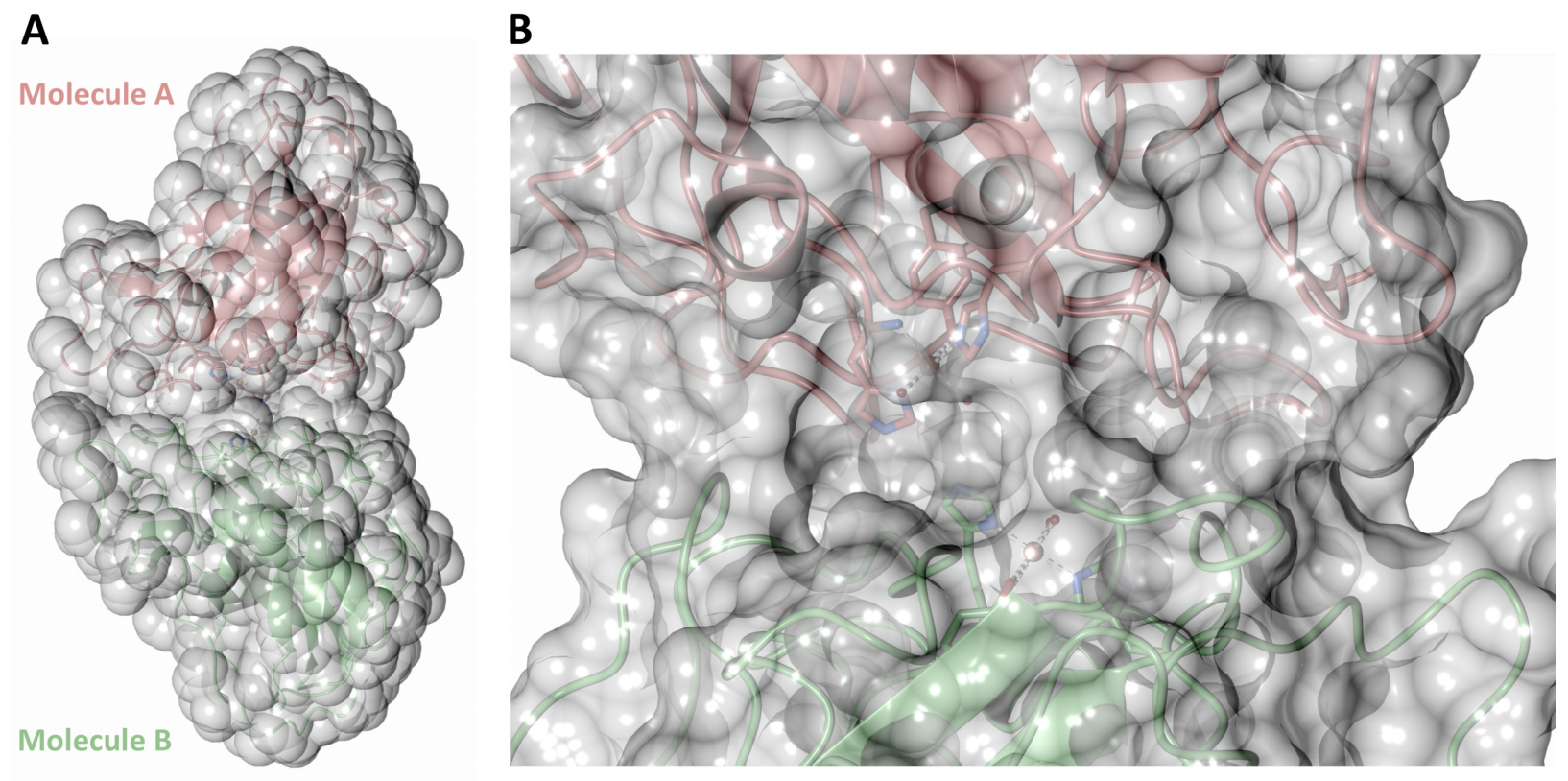

Figure 2 Solvent accessible surface in the crystal packing of Molecule $A$ and Molecule $B$ of the asymmetric unit of LPMO9D. Surface displayed with a probe radius of $1.5 \AA$.

\section{Ascorbate-reduced copper active site}

To probe the protonation states of key catalytic residues and intermediates in the NCLPMO9D active site, a neutron diffraction dataset to $2.4 \AA$ resolution was collected at $100 \mathrm{~K}$ on a crystal of NCLPMO9D reduced with ascorbate at $\mathrm{pD} 6.0(\mathrm{pH} 5.6)$ in the presence of atmospheric oxygen. Structure refinement was performed solely against neutron data to circumvent potential artefacts induced by X-ray radiation damage. The axial position is vacant, supporting displacement of both the equatorial and axial water molecules upon $\mathrm{Cu}^{2+}$ reduction. The neutron scattering length density maps at the active site of Molecule A indicate the presence a fully occupied equatorially coordinated dioxygen species in a mixed state of a two-atom superoxo species and a three-atom hydroperoxo species with occupancies of 0.30 and 0.70 , respectively (Fig. $3 \mathrm{~A}$ and $3 \mathrm{~B}$ ). The intermediates have $\eta_{1}$ end-on geometry at a $\mathrm{Cu}-\mathrm{O} 1$ distance of $\sim 1.96 \AA$ and $\sim 1.98 \AA$ for the superoxo and hydroperoxo species, respectively. The superoxo species is modelled with an O-O bond length of $1.28 \AA$ while the hydroperoxo species is modelled with a bond length of $1.46 \AA$. The $\mathrm{Cu}-01-02$ angles are $\sim 147^{\circ}$ and $151^{\circ}$ for the superoxo and hydroperoxo species respectively. A Glu30 residue from Molecule B is modeled $2.06 \AA$ and $2.08 \AA$ away from the 02 of the 
superoxo and hydroperoxo species, respectively, however it displays a disordered conformation with limited NSLD, as has been observed for NCLPMO9D structures with the same crystal packing. ${ }^{7,30,31}$ The modeling of an activated dioxygen species is in good accordance with our previous high resolution X-ray structures which indicated the presence of a peroxo species with a $1.44 \pm 0.06 \AA$ bond length with a CuO1-O2 angle of $140.52^{\circ}$ and $1.90 \AA$ from the $\mathrm{Cu}$ following ascorbate reduction (Fig. 3D). ${ }^{30}$ Activated dioxygen species have been observed in further LPMO structures including NcLPMO9D and NCPMO-3 from Li et al., JdLPMO10A from Bacik et al. as well as in an artificial copper protein from Mann et al. (Table 1). ${ }^{7,12,25,30,36}$ In our previous high-resolution X-ray structure, discrimination between a putative superoxo and peroxo species was based on bond length determination due to the lack of visibility of hydrogen atoms. In addition, the occupancy of the activated dioxygen species only refined to 0.59 and an axial water remained present with an occupancy of 0.48 . We reason that photoreduction due to X-ray beam exposure resulted in an intermediates with reduced occupancy. The NcLPMO9D active site presented here is absent of radiation damage since neutron protein crystallography is a non-destructive technique permitting capture of a mixed occupancy of a superoxo and hydroperoxo species. ${ }^{28}$ The observed hydroperoxo species may represent an intermediate in the mechanism of LPMO-catalyzed $\mathrm{H}_{2} \mathrm{O}_{2}$ formation, since LPMOs are known to produce $\mathrm{H}_{2} \mathrm{O}_{2}$ in the absence of substrate. ${ }^{37}$ Caldararu et al. have further shown it is more energetically favorable for $\mathrm{H}_{2} \mathrm{O}_{2}$ formation to proceed by dissociation of $\mathrm{H}_{2} \mathrm{O}_{2}$ from the copper active site than $\mathrm{HO}_{2} \cdot{ }^{25}$ This higher dissociation energy of $\mathrm{HO}_{2}$ is supported by the observed binding stability of the hydroperoxo species in our structure.

The Molecule B copper active site contains a water molecule coordinated in the axial position with a partial occupancy of 0.65 and a Cu-O distance of $\sim 2.2 \AA$ while the equatorial position is vacant (Fig. 3C). This geometry, while not chemically relevant, has been observed in partially photo-reduced LPMO structures, ${ }^{38}$ suggesting that the active site of Molecule B underwent only partial reduction during the 
ascorbate soak. We attribute the differences between Molecule $A$ and Molecule $B$ to the conformations of the Tyr residues at the binding interfaces.

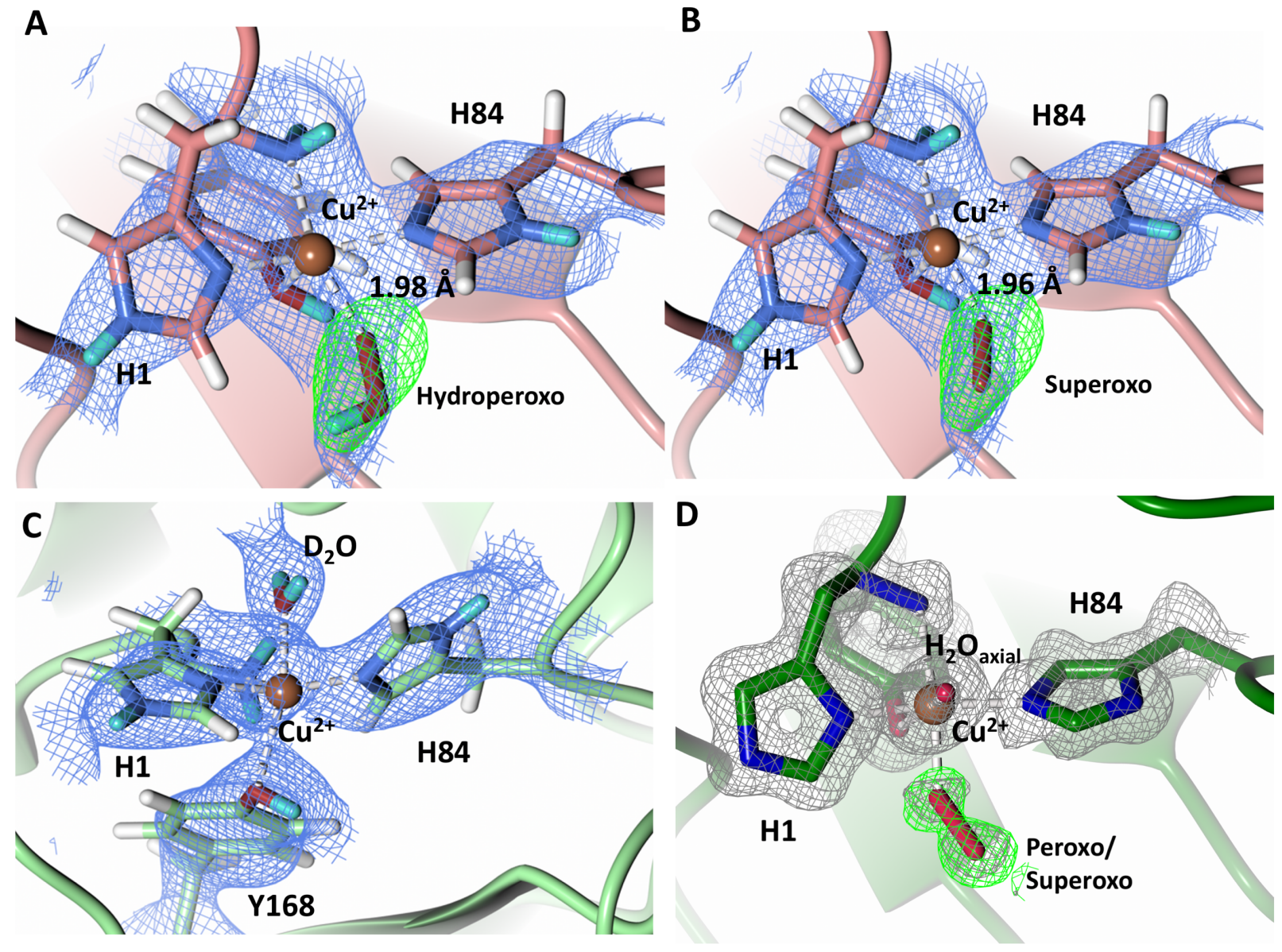

Figure 3 Neutron diffraction structure of the ascorbate reduced LPMO9D crystal. (A) Active site of Molecule A (coral) with a hydroperoxo species bound at the equatorial position. (B) Active site of Molecule A (coral) with a superoxo species bound at the equatorial position. (C) Active site of Molecule B (light green) with a water bound at the axial position. (D) Equatorially coordinated activated dioxygen superoxo/peroxo in X-ray diffraction structure of ascorbate reduced LPMO9D (green) by O'Dell et al. ${ }^{30}$ (PDB 5TKH). Neutron scattering length density $2 F_{\mathrm{o}}-F_{\mathrm{c}}$ maps displayed in blue at a $1.0 \sigma$ cut-off. Neutron scattering length density $F_{\mathrm{o}}-F_{\mathrm{c}}$ maps displayed in green at a $2.5 \sigma$ cut-off. $\mathrm{H}$ atoms displayed in white and $\mathrm{D}$ atoms displayed in turquoise. Electron density $2 F_{\mathrm{o}}-F_{\mathrm{c}}$ maps displayed in grey at a $1.0 \sigma$ cut-off. Electron density $F_{\mathrm{o}}-F_{\mathrm{c}}$ maps displayed in green at a $3.0 \sigma$ cut-off. 
Table 1 Structurally characterized dioxygen species in LPMOs.

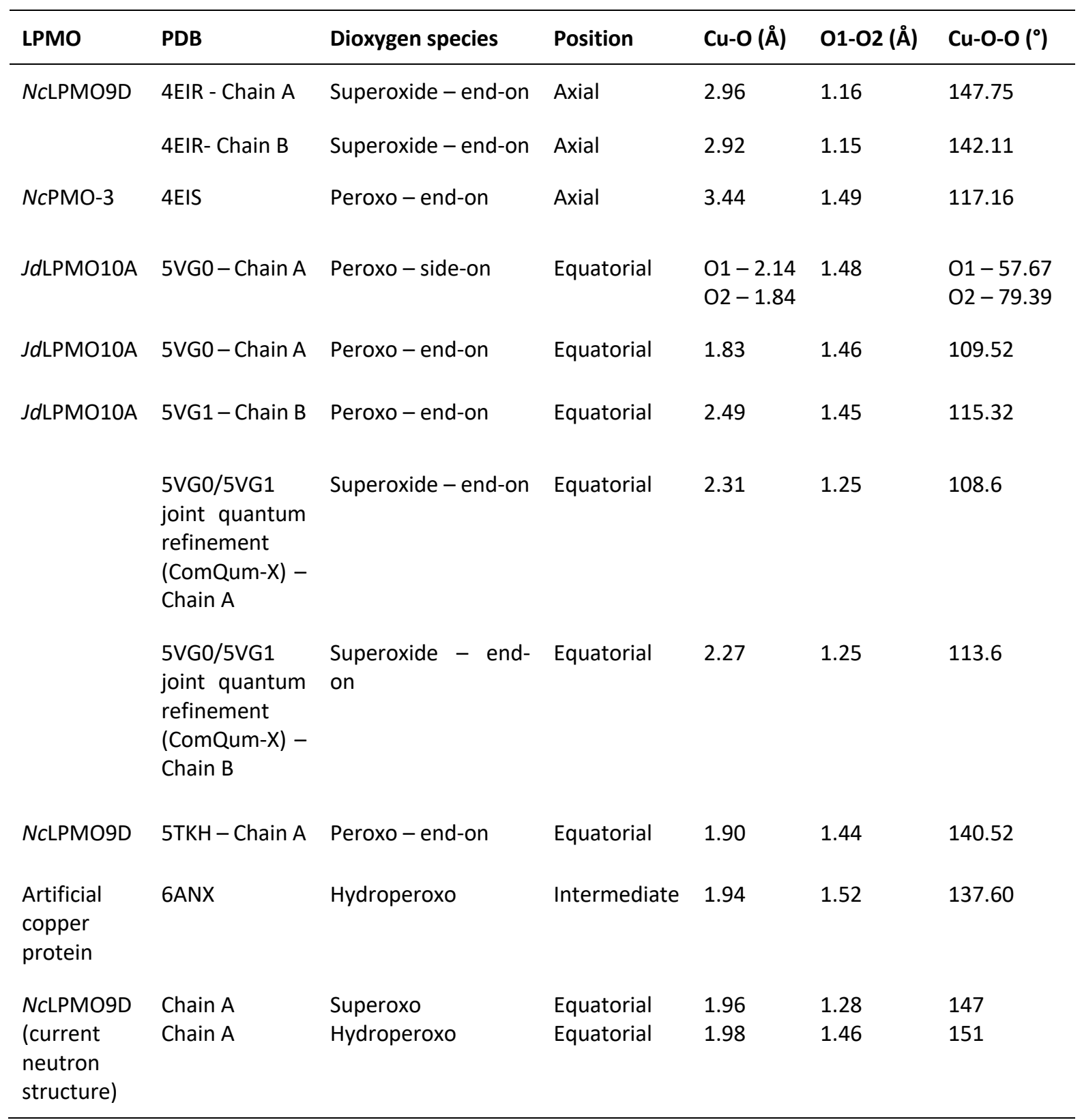

\section{Protonation state of His157}

Testing of different protonation states and visual examination of the $2 F_{\mathrm{o}}-F_{\mathrm{c}}$ and $F_{\mathrm{o}}-F_{\mathrm{c}}$ omit neutron scattering length density maps of the Molecule A secondary coordination shell His157 suggest that this residue is best modelled by the neutral $\mathrm{N}_{\varepsilon^{-}}$protonated form and the imidazolate form with occupancies of 0.30 and 0.70 , respectively (Fig. 4A and 4B). Analysis of the Molecule B neutron scattering length density 
maps indicate that His157 is singly $\mathrm{N}_{\varepsilon}$-protonated at full occupancy (Fig. 4 C). The $\mathrm{N}_{\varepsilon}$ nitrogen of His157 in Molecule $\mathrm{A}$ is observed at a distance of $\sim 3.0 \AA$ from the distal oxygen $\mathrm{O} 2$ of the equatorially bound superoxo species and hydroperoxo species. These findings indicate that His157 plays a role in protonation of the activated dioxygen species observed in the barricaded active site presented here. Activity and structural studies of MtPMO3* as well as QM/MM calculations of LsLPMO9A have implicated this conserved histidine residue in proton transfer to the copper-bound superoxide during LPMO catalysis (His161 and His147 in MtPMO3* and LsLPMO9A, respectively). ${ }^{22,24}$ QM/MM studies have also indicated that the Glu201 residue near the copper active site in JdLPMO10A is capable of donating a proton to a bound superoxo to form a hydroperoxo species. ${ }^{25}$ Computational studies have suggested that ascorbate may function as a proton donor to the superoxo species; ${ }^{26}$ however, the active site occlusion due to crystal packing in our structure does not permit ascorbate to access the copper active site, and there was no evidence in the NSLD maps for an ascorbate molecule near the active site. Following formation of the superoxide in NcLPMO9D, protonation by His157 may form the copper(II)-hydroperoxyl species $[\mathrm{CuOOH}]^{2+}$, the copper(III)-hydroperoxo $[\mathrm{CuOOH}]^{2+}$, or upon further reduction a copper(II)-hydroperoxo $[\mathrm{CuOOH}]^{+}$, all of which have been posited as viable reaction intermediates. ${ }^{12,23,39,40}$

\author{
Superoxo: $[\mathrm{Cu}]^{+}+\mathrm{O}_{2} \rightarrow\left[\mathrm{Cu}-\mathrm{O}_{2}\right]^{+}$ \\ Hydroperoxyl radical/Hydroperoxo: $\left[\mathrm{Cu}-\mathrm{O}_{2}\right]^{+}+\mathrm{H}^{+} \rightarrow[\mathrm{Cu}-\mathrm{OOH}]^{2+}$ \\ Hydroperoxo: $\left[\mathrm{Cu}-\mathrm{O}_{2}\right]^{+}+\mathrm{H}^{+}+\mathrm{e}^{-} \rightarrow[\mathrm{Cu}-\mathrm{OOH}]^{+}$
}

While the neutron data supports modeling of a two and three atom dioxygen species at the active site, it does however not permit definitive discrimination between the hydroperoxyl or hydroperoxo species nor does it resolve the redox state of the copper ion. We performed DFT studies on active site models to further assess the intermediates modelled in the copper active site of Molecule A (Table 2). The 
calculations indicate that the $\mathrm{N}_{\varepsilon^{-}}$protonated His157 plus superoxo species and the imidazolate plus hydroperoxo species are both stable states in that they both remain bound when geometry optimized to a stationary point on the potential energy surface; however, they each have a different combination of charge and copper spin state (Table 2) precluding a direct comparison of their DFT calculated energies. The second reduction to form the hydroperoxo species can potentially be derived from ascorbate by longrange intramolecular electron transfer to the active site as has been proposed to occur via LPMO aromatic residues localized near the copper active site..$^{5,741,42}$ An accurate calculated energy difference between the two states will require a multi-determinant $\mathrm{QM}$ treatment due to propensity of copper centers to exhibit multiple near degenerate electronic states. This will be addressed in planned future calculations using $\mathrm{QM} / \mathrm{MM}$ with a multi-determinant wavefunction $\mathrm{QM}$ method.

Table 2 Stability and electronic state of DFT models.

\begin{tabular}{|c|c|c|c|c|c|c|}
\hline Model & $\begin{array}{l}\text { DFT active site } \\
\text { residues }\end{array}$ & $\begin{array}{c}\text { Starting } \\
\text { proton position }\end{array}$ & $\begin{array}{c}\text { System } \\
\text { net charge }\end{array}$ & Multiplicity & Stability & Final state \\
\hline $\begin{array}{l}\text { Superoxo, His157 } \\
\text { NE2-protonated }\end{array}$ & $\begin{array}{l}\text { His1, His84, His157, } \\
\text { Gln166, Tyr168 }\end{array}$ & His157 NE2 & +1 & 2 & Stable & $\begin{array}{l}\text { His157 singly } \\
\text { NE2- } \\
\text { protonated }\end{array}$ \\
\hline $\begin{array}{l}\text { Hydroperoxyl } \\
\text { radical, His157 } \\
\text { doubly } \\
\text { deprotonated }\end{array}$ & $\begin{array}{l}\text { His1, His84, His157, } \\
\text { Gln166, Tyr168 }\end{array}$ & $\mathrm{O}-\mathrm{O}-\mathrm{H}$ & +1 & 2 & Stable & $\begin{array}{l}\text { Double } \\
\text { deprotonated } \\
\text { His157 }\end{array}$ \\
\hline $\begin{array}{l}\text { Hydroperoxo, } \\
\text { His157 doubly } \\
\text { deprotonated }\end{array}$ & $\begin{array}{l}\text { His1, His84, His157, } \\
\text { Gln166, Tyr168 }\end{array}$ & $\mathrm{O}-\mathrm{O}-\mathrm{H}$ & 0 & 2 & Stable & $\begin{array}{l}\text { Double } \\
\text { deprotonated } \\
\text { His157 }\end{array}$ \\
\hline $\begin{array}{l}\text { Hydroperoxo, } \\
\text { His157 doubly } \\
\text { deprotonated }\end{array}$ & $\begin{array}{l}\text { His1, His84, His157, } \\
\text { Gln166, Tyr168 }\end{array}$ & $\mathrm{O}-\mathrm{O}-\mathrm{H}$ & -1 & 1 & Stable & $\begin{array}{l}\text { Double } \\
\text { deprotonated } \\
\text { His157 }\end{array}$ \\
\hline
\end{tabular}



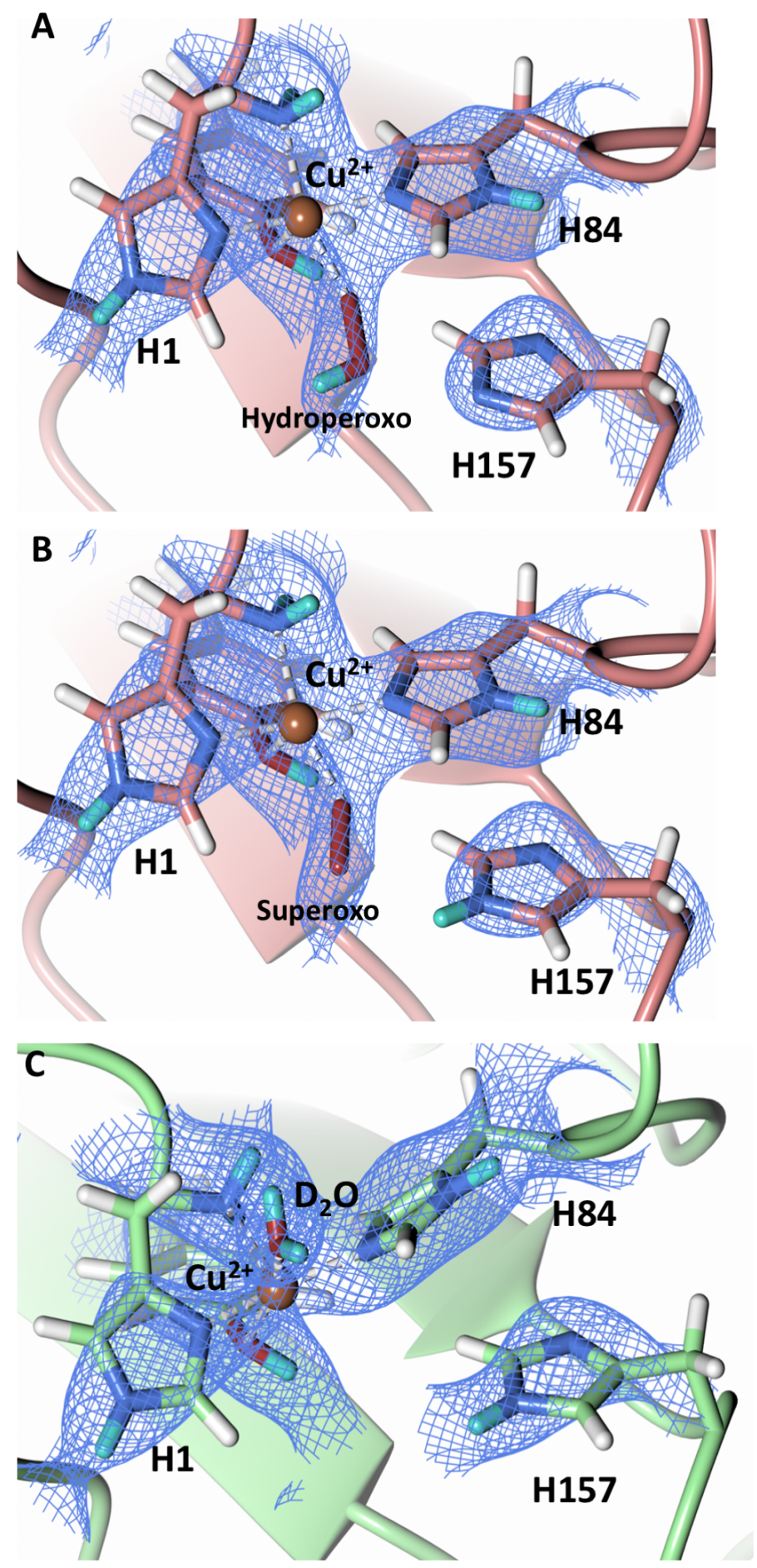

Figure 4 Mixed protonation state His157 in ascorbate reduced LPMO9D. (A) The Molecule A (coral) second shell His157 is deprotonated with an equatorial hydroperoxo species coordinated to $\mathrm{Cu}^{2+}$. (B) The Molecule $A$ second shell His 157 is singly $\mathrm{N}_{\varepsilon}$-protonated with an equatorial superoxo species coordinated to $\mathrm{Cu}^{2+}$. (C) The Molecule B (light green) second shell His157 is singly $\mathrm{N}_{\varepsilon}$-protonated with an axial water coordinated to $\mathrm{Cu}^{2+}$. Neutron scattering length density $2 F_{\mathrm{o}}-F_{\mathrm{c}}$ maps displayed in blue at a $1.0 \sigma$ cut-off. $\mathrm{H}$ atoms displayed in white and $D$ atoms displayed in turquoise. 


\section{Active site protonation following initial dioxygen activation}

The $\mathrm{N}$-terminal amino group of the histidine brace has been postulated to play a role in intermediate formation and stabilization during LPMO catalysis. ${ }^{43}$ A previous neutron protein crystallography study of unreduced JdLPMO10A, a bacterial LPMO, suggested that the amino terminal is present as a mixture of the $-\mathrm{ND}^{-}$and $-\mathrm{ND}_{2}$ protonation states. ${ }^{36}$ The $J d \mathrm{LPMO} 10 \mathrm{~A}$ neutron structure was, however, later revisited and a joint X-ray-neutron quantum refinement concluded that the amino terminal is present solely in the $-\mathrm{ND}_{2}$ state. ${ }^{25}$ We therefore sought to determine the protonation state of the N-terminal amino group upon NcLPMO9D reduction by ascorbate in the presence of atmospheric $\mathrm{O}_{2}$. The neutron scattering length density map indicates that both Molecule A and Molecule B contain the amino terminal in the $-\mathrm{ND}_{2}$ protonation state. $F_{\mathrm{o}}-F_{\mathrm{c}}$ omit difference maps calculated confirm the $-\mathrm{ND}_{2}$ state in both Molecule A and Molecule B (Fig. 5A - 5D). The role of possible deprotonation of the N-terminal histidine amino group came to the forefront when it was proposed to promote reactive intermediate formation and stabilization based on findings from a small molecule copper complex. ${ }^{44}$ Structural and spectroscopic studies of a substrate-bound LsLPMO9A suggested that the two protons of the N-terminus are exposed to different chemical environments, with one being involved in a hydrogen bond network, which potentially promotes $\mathrm{N}$-terminal deprotonation during LPMO catalysis. ${ }^{35}$ Our neutron protein crystallography structures show that the $\mathrm{N}$-terminal amine is not involved in protonation upon initial $\mathrm{Cu}^{2+}$ reduction and molecular dioxygen activation. However, a mechanistic role for the $\mathrm{N}$-terminal amine in other contexts cannot be conclusively ruled out by our experiments. 


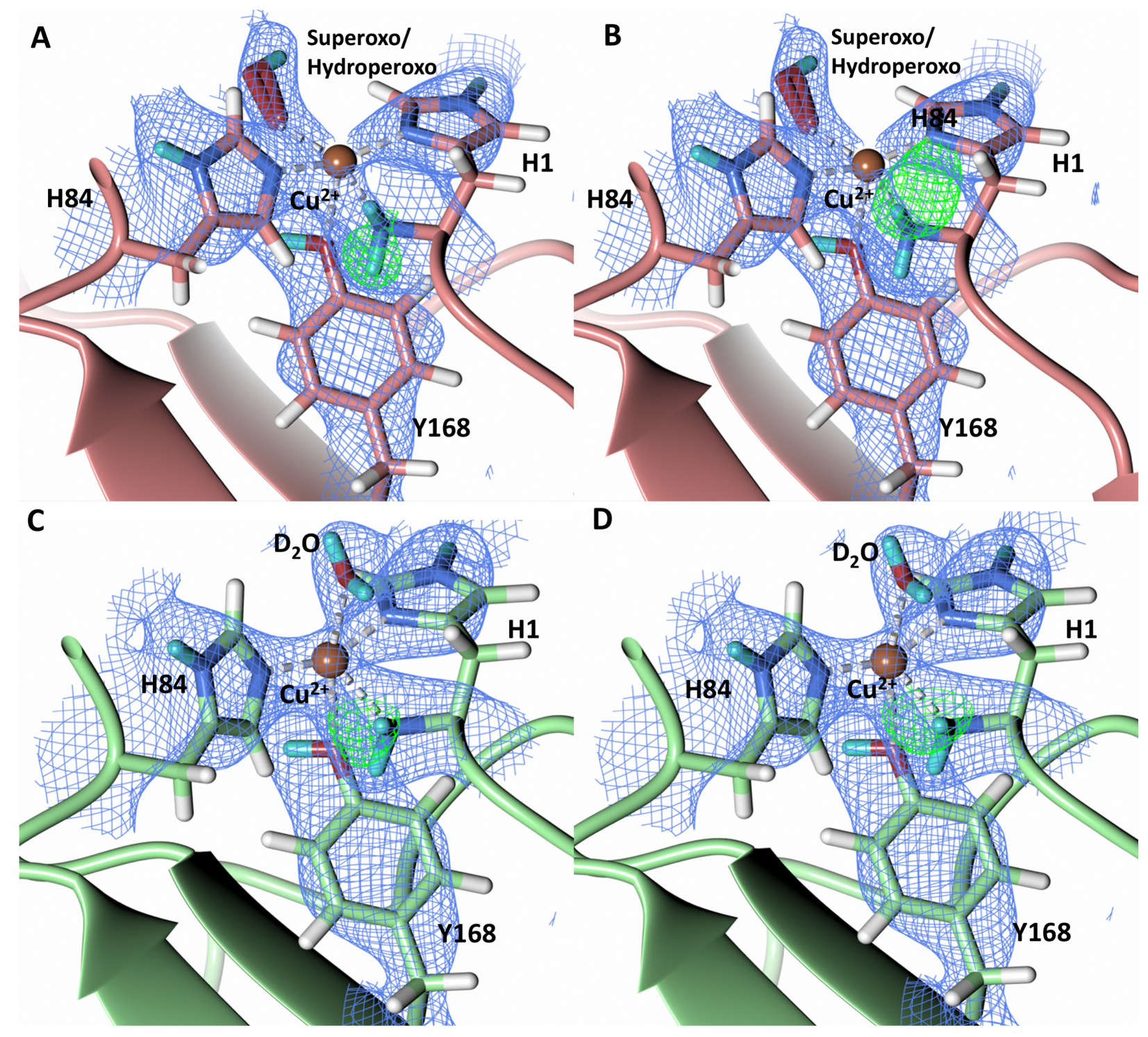

Figure 5 Protonation state of the N-terminal His157 amino group in the ascorbate reduced LPMO9D crystal. (A) Molecule A (coral) omit map displaying D2-protonation and (B) D3-protonation of the Nterminal nitrogen. (C) Molecule B (light green) omit map displaying D2-protonation and (D) D3protonation of the $\mathrm{N}$-terminal nitrogen. Neutron scattering length density $2 F_{\mathrm{o}}-F_{\mathrm{c}}$ maps displayed in blue at a $1.0 \sigma$ cut-off. Neutron scattering length density $F_{\mathrm{o}}-F_{\mathrm{c}}$ maps displayed in green at a $3.0 \sigma$ cut-off. $\mathrm{H}$ atoms displayed in white and $D$ atoms displayed in turquoise.

A study by Paradisi et al. on LsAA9 spectroscopically detected a radical $\mathrm{Cu}^{2+}$-tyrosyl complex in which the axial Tyr164 was present as a deprotonated radical following reaction with $\mathrm{H}_{2} \mathrm{O}_{2}$ following ascorbate reduction. ${ }^{45}$ This tyrosyl radical intermediate formed irreversibly and was inactive toward substrate, indicating that it may play a role in active site protection during uncoupled turnover. A further 
spectroscopic study on TaLPMO9A by Singh et al. isolated a $\mathrm{Cu}^{2+}$-tyrosyl radical intermediate following ascorbate reduction and addition of $\mathrm{H}_{2} \mathrm{O}_{2}{ }^{46}$ The long-lived Tyr175 radical intermediate was spectroscopically distinct from the tyrosyl radical observed in LsAA9 and was proposed to play a role in active site protection from oxidation or be involved in substrate oxidation. To address the observation of the two radical species, McEvoy et al. performed QM/MM to model the feasibility of both deprotonated tyrosyl radical species. ${ }^{47}$ The intermediate observed by Singh et al. was proposed to be to a cis-[Tyr-CuOH] ${ }^{+}$ formed by hydrogen transfer from the tyrosine hydroxy to an oxyl species in the equatorial plane. The intermediate observed by Paradisi et al. was characterized as a trans-[Tyr-CuOH$]^{+}$which can be formed through internal hydrogen transfer from a water molecule axially coordinated to the copper. Calculations of reactivity of these tyrosyl radical species toward the substrate however indicated limited reactivity, further supporting a protective role for tyrosine to prevent oxidative damage. Given these observations of a tyrosine acting as a proton donor to form a deprotonated phenoxyl species, we further examined the protonation state of Ty168 in the copper axial position of LPMO9D. $F_{\mathrm{o}}-F_{\mathrm{c}}$ omit difference maps in both Molecule A and B indicate Tyr168 remains in the protonated form (Fig. 6), excluding it as a proton donor the early stages of dioxygen activation. 


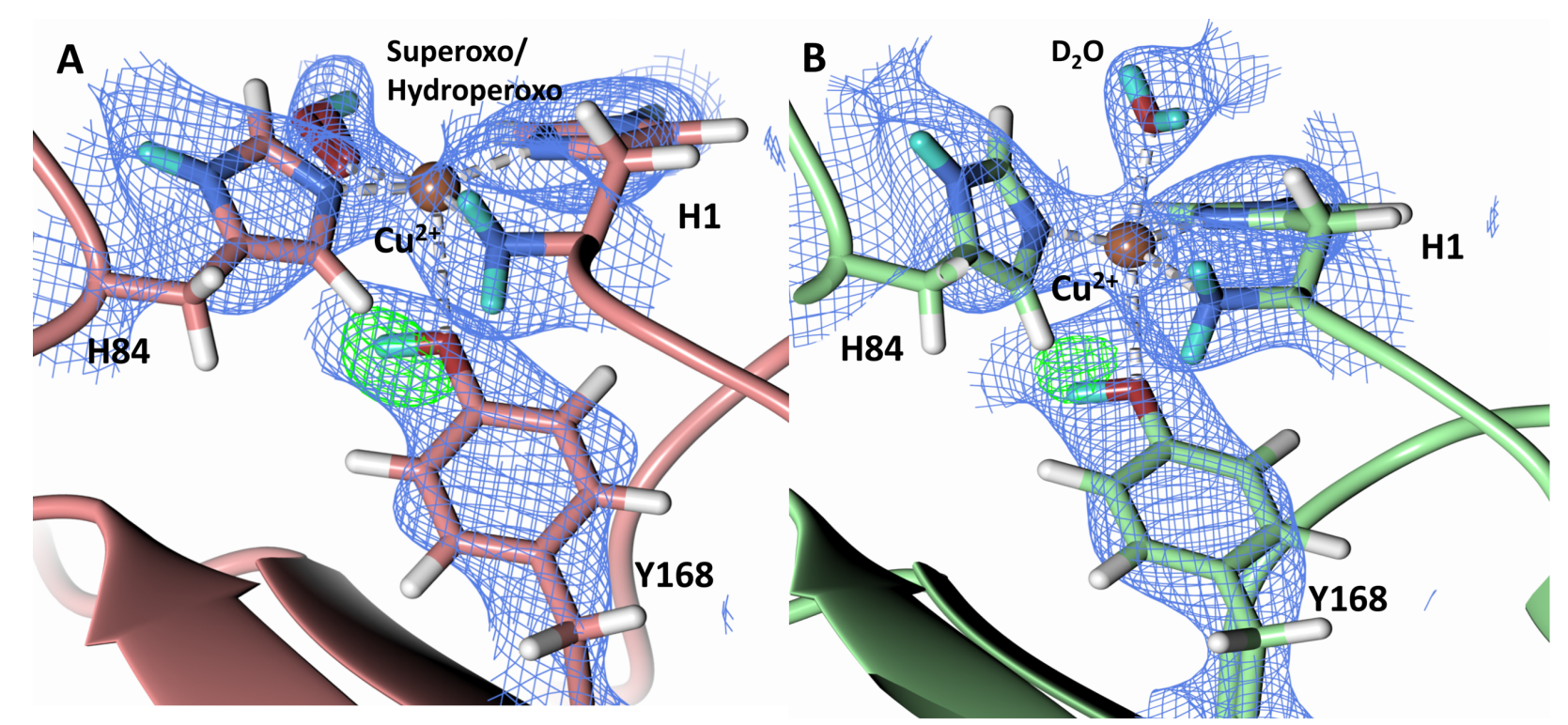

Figure 6 Protonation state of the Tyr168 in the ascorbate reduced LPMO9D crystal. (A) Molecule A (coral) omit map displaying DH-protonation and (B) Molecule B (light green) omit map displaying $\mathrm{DH}-$ protonation. Neutron scattering length density $F_{\mathrm{o}}-F_{\mathrm{c}}$ maps displayed in green at a $3.0 \sigma$ cut-off. $\mathrm{H}$ atoms displayed in white and $\mathrm{D}$ atoms displayed in turquoise.

\section{Histidine protonation at acidic conditions}

During LPMO catalysis, a second shell histidine has been proposed to be involved in protonation of active site intermediates with $\mathrm{QM} / \mathrm{MM}$ studies by Hedegård and Ryde on LsAA9A suggesting that His147 in a doubly protonated state can act as a proton donor. ${ }^{22}$ Additionally, Span et al. have proposed that His 161 in MtPMO3 plays a role as a proton donor based on structural, mutagenesis and spectroscopic studies as well as activity assays. ${ }^{24}$ LPMOs are expected to catalyze oxygen insertion under acidic conditions since they function synergistically alongside cellulases which show optimum activity at pH 3.5 - 5.5. ${ }^{48-50}$ Given the surprising role of a neutral His157 as a proton donor to the activated dioxygen species in our structure, we sought to probe the protonation state of His157 when exposed to acidic buffer conditions. We collected a 2.14 Å room-temperature neutron diffraction dataset under low pH conditions (pH 4.4/pD 4.8) achieved by vapor exchange of the crystal with acidified buffer. Analysis of the nuclear scattering length density maps indicate that the His157 residue remains singly protonated at the $\mathrm{N}_{\varepsilon^{-}}$ position at this $\mathrm{pH}$, which is supported by $F_{0}-F_{c}$ omit difference maps in both Molecule $A$ and $B$ (Fig. 7). To further support our acidic $\mathrm{pH}$ structure obtained by vapor exchange, a $1.5 \AA$ X-ray dataset was collected 
on a crystal directly soaked in acidic buffer. The position of His157 at pH 4.4 superimposes to its position at $\mathrm{pH}$ 6.0. In this position, $\mathrm{N}_{\delta}$-protonation would sterically clash with the backbone amide proton, further supporting the single $\mathrm{N}_{\varepsilon}$-protonation state observed in the neutron structure (Fig. S6 and S7). The barricaded active site observed in crystallo and electropositive environment of the copper potentially play a role in maintaining the observed single histidine protonation state and prevent formation of protonation pathways to the active site. In both the neutron and X-ray low $\mathrm{pH}$ structures, the copper remains coordinated in the histidine brace, contrary to the disordered His78 observed in LsLPMO9A at pH 3.5 (PDB 5N04). ${ }^{51}$ The low $\mathrm{pH}$ structure of $L s L P M O 9 A$ was obtained using high $\mathrm{NaCl}$ concentrations, however, resulting in $\mathrm{His} 78$ displacement by a chloride anion. The absence of $\mathrm{NaCl}$ in our crystallization conditions precludes coordinating histidine residue displacement by a chloride anion.
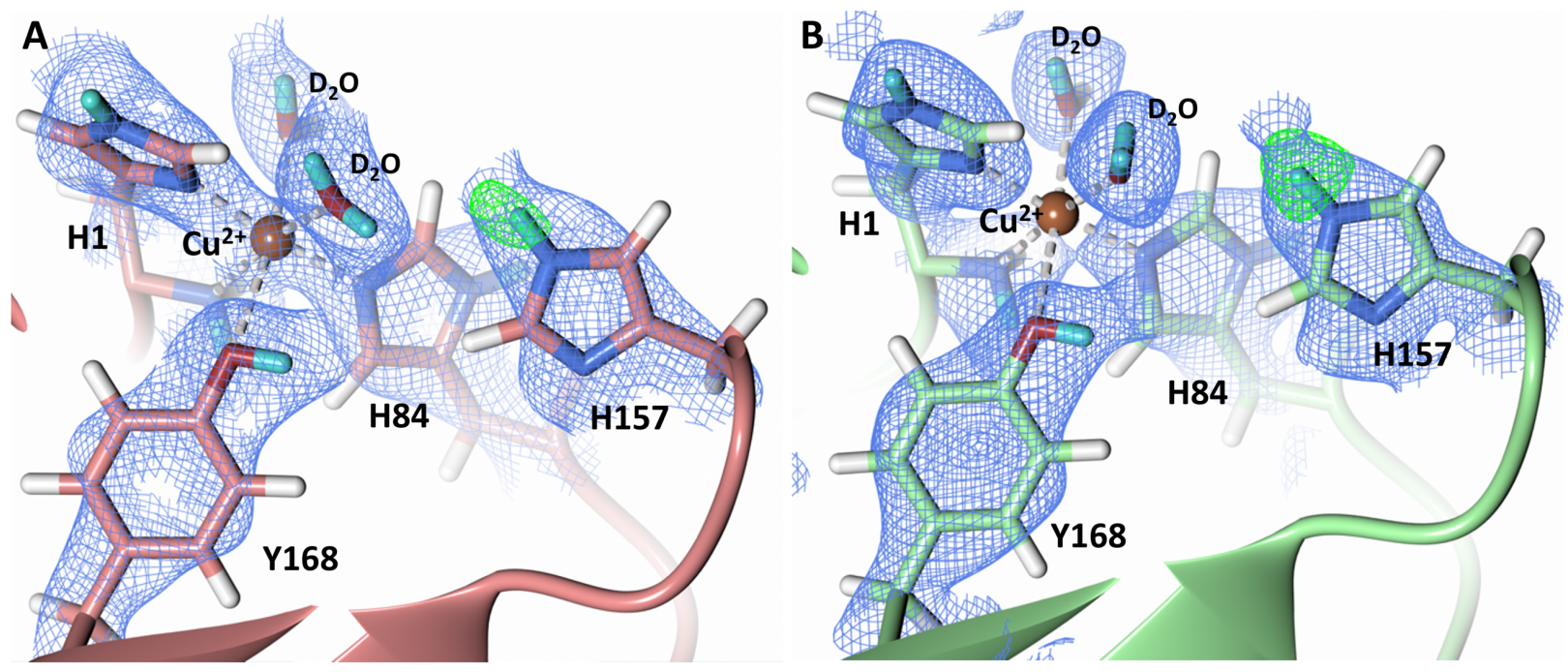

Figure 7 Protonation state of second-shell His157 at acidic conditions. (A) Molecule A (coral) His157 $\mathrm{N}_{\varepsilon^{-}}$ protonation. (B) Molecule $B$ (light green) His157 $\mathrm{N}_{\varepsilon}$-protonation. Neutron scattering length density $2 F_{\mathrm{o}}-F_{\mathrm{c}}$ maps displayed in blue at a $1.0 \sigma$ cut-off. Neutron scattering length density $F_{\mathrm{o}}-F_{\mathrm{c}}$ maps displayed in green at a $3.0 \sigma$ cut-off. $\mathrm{H}$ atoms displayed in white and $\mathrm{D}$ atoms displayed in turquoise. 


\section{Conformational flexibility of His157}

Analysis of the crystal structure of MtPMO3* deposited by Span et al. indicate that the second shell His161 corresponding to NcLPMO9D His157 is present in two conformations: an "inward" copperfacing conformation with a with a Cu- $\mathrm{N}_{\varepsilon}$ distance of $~ 5 \AA$, and an "outward" copper-distant conformation with a Cu-N $\mathrm{N}_{\varepsilon}$ distance of $10 \AA$ (Fig. 8). ${ }^{24}$ The experimentally observed existence of both "inward" and "outward" conformations indicates mobility of the conserved second shell histidine, at least when the copper active site is solvent exposed.

The flexibility of His157 was investigated using molecular dynamics (MD) simulations of LPMO, in the monomeric form to avoid artifacts from crystal packing. The MD simulation starting from structure reported here (with His157 in the inward conformation) did not show any snapshots with the outward conformation at a 1 microsecond timescale. However, we also performed MD simulations based on a related LMPO (PDB ID = 5UFV, monomer A), which indicated that His161 (at equivalent position to His157) is able to freely interconvert between the inward and outward conformations at the microsecond timescale (more than 10 transitions between inward and outward conformations were observed in 1 microsecond MD simulation). Therefore, we hypothesized that His157 in our structure is possibly trapped in a conformation which makes it difficult to explore outward conformation at the microsecond timescale. Note, as described in the methods section, 6 distance restraints were applied with the neighboring atoms to keep $\mathrm{Cu}$ in the active-site. The MD simulation based on 5UFV also used restraints between $\mathrm{Cu}$ and the equivalent residues, which excludes the possibility that the lack of interconversion between the inward and outward conformation in MD based on our structure is due to the use of distance restraints. To further explore the conformational flexibility, we performed another MD simulation starting from outward conformation (see details below). In this MD simulation, His157 was able to interconvert to the inward conformation at the microsecond timescale (only twice), confirming our hypothesis of dynamic interconversion of His157. However, once fully in the inward conformation, even in this MD simulation 
His157 stayed locked in that position. It is interesting that the two related LPMOs show difference in the rates of His157 (and equivalent His161) conformation interconversion, which could also have a functional role possibly associated with sampling of certain conformational events required in the catalytic cycle as has been observed in several other enzyme systems. ${ }^{52}$

To further probe the extent of such local flexibility and the associated energetics in our own structure, we carried out $2^{\text {nd }}$-generation mining minima (VM2) free energy calculations, ${ }^{53-56}$ and compared the predicted thermodynamically accessible NcLPMO9D His157 conformations found when the active site is solvent exposed to those found when the active site is in the crystal structure with binding-face to binding-face packing.

When applied to NCLPMO9D with its active site exposed to solvent (i.e. the monomeric structure), the VM2 method, which performs extensive molecular conformational searching and provides a total free energy via a Boltzmann weighted ensemble of the resultant low energy conformers, predicts that both "inward" and "outward" His157 confirmations are populated. Focusing only on the two lowest energy conformers found by VM2 (Fig. 9), the first conformer is "inward" and the second conformer is "outward" with a free energy difference of only $0.11 \mathrm{kcal} \mathrm{mol}^{-1}$ between them. A representative structure from these calculations with His157 in the outward conformation was used as the starting model of the MD simulations previously described. Furthermore, summing the probabilities of each type of conformation populated, so that $99.0 \%$ of the total population is included, His157 has a predicted 3:1 "inward" to "outward" probability distribution. In contrast, when applied to the NCLPMO9D dimer, as per the crystal structure (Fig. 1A), VM2 finds only conformations where His157 remains fully "inward". This is despite VM2's ability to drive molecular conformations over large energy barriers, as well as a free energy window set at $10 \mathrm{kcal} \mathrm{mol}^{-1}$ for retaining minima found by the conformational search. This result strongly supports preclusion of movement of His157 to an "outward" conformation due to the barricaded active site present in the crystal structure. An estimate of the barrier between the inward and outward conformation was 
obtained using a combination of the MD simulations and VM2 calculations. Selected conformation ranging between the two extremes were selected from MD simulations and the relative energy were obtained using VM2 calculations. These calculations suggest that the barrier is about $11.0 \mathrm{kcal} / \mathrm{mol}$ from the inward to outward conformation, and about $12.1 \mathrm{kcal} / \mathrm{mol}$ from the outward to the inward conformation. More details are available in the SI.

We conclude, then, that the steric obstruction resulting from crystal packing of the dimer has significantly limited the conformational flexibility of His157 and suggest that the likely mobility of this residue in the monomer, which has a solvent exposed active site, may facilitate its protonation and serve a functional role. Taken together with the crystal structure active site occlusion, these factors may explain the single $\mathrm{N}_{\varepsilon}$-protonation of His157 observed even at acidic conditions. However, the single protonation of His157 solely at the $\mathrm{N}_{\varepsilon}$ position in our crystal structures does not rule out formation of the doubly protonated second shell histidine residue under similar acidic operando conditions where the active site would not be barricaded by crystal packing.

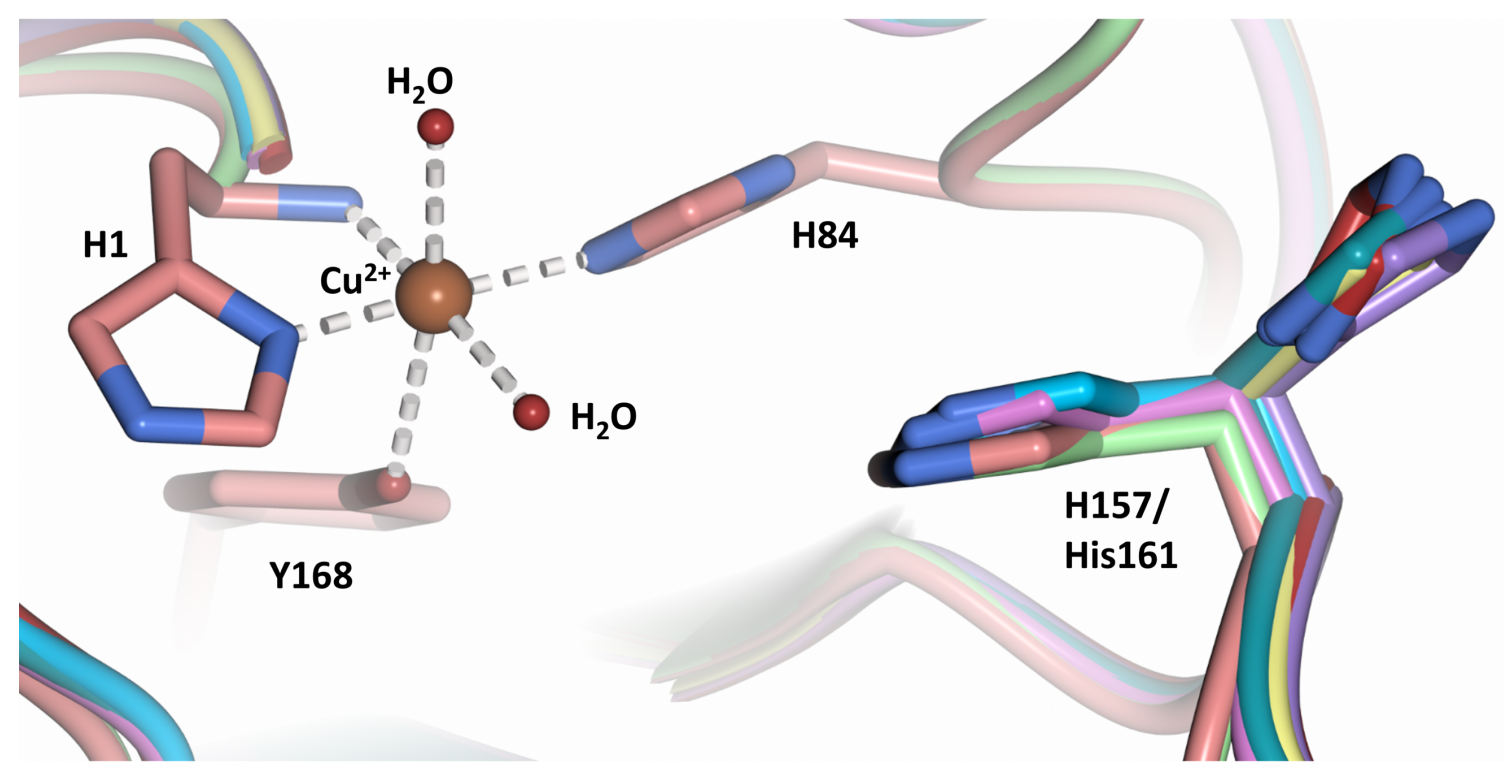

Figure 8 Alignment of a second shell residue His157 in the "inward" and "outward" conformation. Alignment of Molecule A MtPMO3* His161 (PDB 5UFV) Molecule A (teal), Molecule B (yellow), Molecule $C$ (pink), Molecule D (purple), Molecule E (turquoise) and Molecule $F$ (red) with NcLPMO9D His157 from Molecule A (coral) and Molecule B (green). 


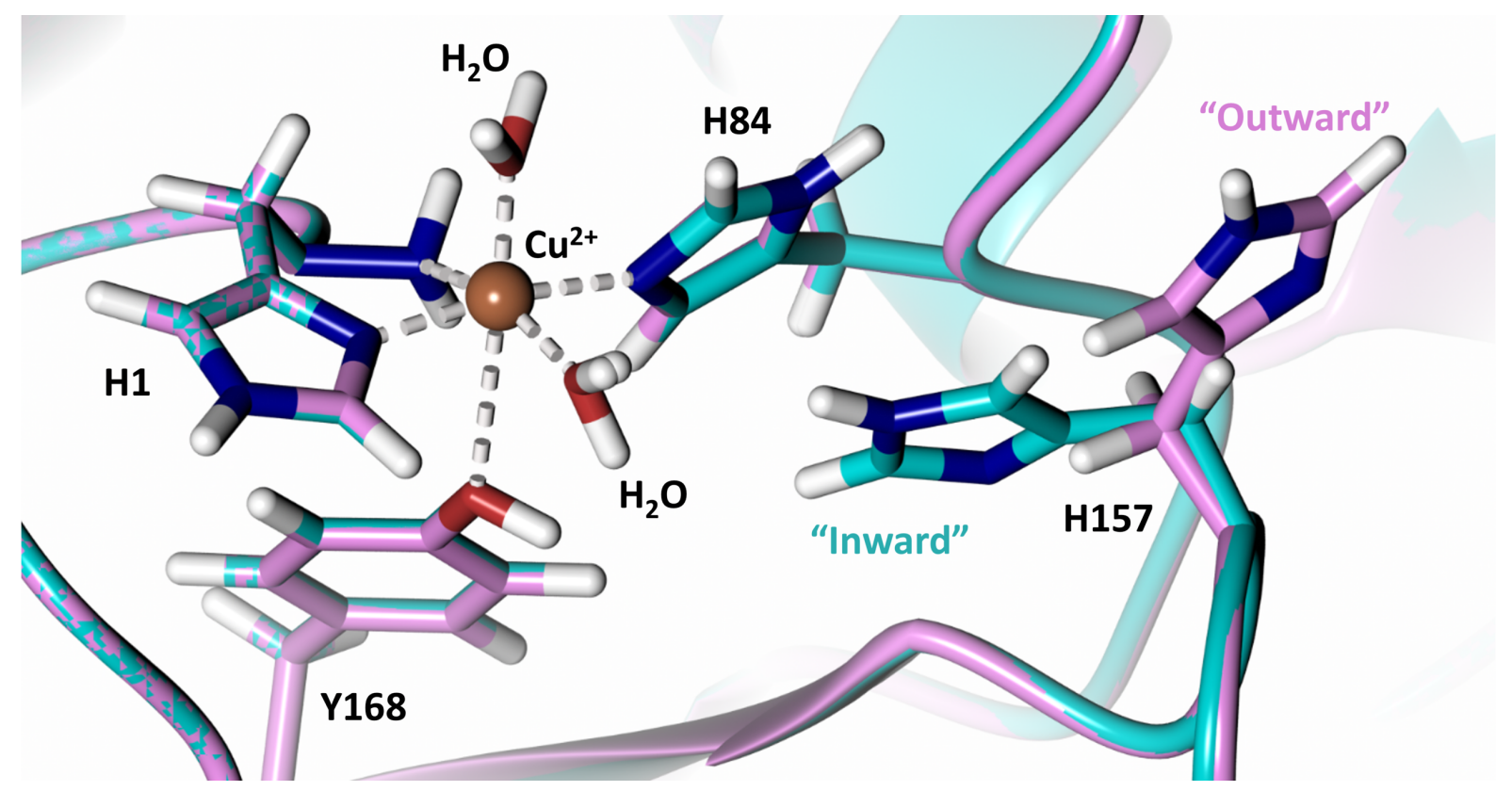

Figure 9 Second shell His157 conformations from VM2 free energy minima calculations. For NcLPMO9D with its active site exposed to solvent His157 adopts an "inward" (cyan) and "outward" (pink) conformation. The inward and outward conformations are separated by a $0.11 \mathrm{kcal} \mathrm{mol}^{-1}$. $\mathrm{H}$ atoms displayed in white. 


\section{Conclusion}

The neutron structure presented here provides a full-atom snapshot of the early catalytic intermediates in the LPMO reaction pathway. Our results provide the first direct observation of a cryotrapped protonated copper-dioxygen species at the LPMO active site. The unique occluded active site environment found in the crystal structure presented here has resulted in stabilization of an activated dioxygen species at the NCLPMO9D active site with joint occupancy as a superoxo intermediate and a hydroperoxo intermediate, potentially to ultimately form $\mathrm{H}_{2} \mathrm{O}_{2}$ in the absence of substrate. A second-shell histidine was further observed in a single $\mathrm{N}_{\varepsilon}$-protonation state and in the imidazolate form, leading us to postulate that it plays a role in the early stages of dioxygen intermediate protonation in the unique barricaded environment provided by the binding-face to binding-face crystal packing. Although unusual, a neutral histidine functioning as a general acid has been mechanistically proposed for the His95 residue in triose phosphate isomerase and the His98 residue in methylglyoxal synthase. ${ }^{57-59}$ It remains to be determined whether the role of the second shell His157 in protonation of the activated dioxygen species prevails operando when NCLPMO9D is solvent-exposed and intermittently binds substrate. The flexibility of His157 and potentially that of neighboring active site residues may serve a role in catalysis that must be further explored. 


\section{Experimental section}

A detailed account of the experimental procedure, data collection and refinement strategy has been described. ${ }^{60}$ Provided here are the experimental details in brief.

\section{Protein expression and crystallization}

Neurospora crassa LPMO9D (NcPMO-2) was heterologously expressed in the Pichia pastoris SuperMan ${ }_{5}$ strain and purified and crystallized as described by $\mathrm{O}^{\prime}$ Dell et al. previously ${ }^{30,31}$ Crystal quality was assessed on beamline CG4-D, the IMAGINE instrument at the High Flux Isotope Reactor at Oak Ridge National Laboratory. ${ }^{61}$

\section{Crystal ascorbate soak and data collection}

To reduce the copper active site, a large crystal was harvested and placed in a deuterated buffer containing 100 mM HEPES pD 6.0 (pH 5.6), 25 \% PEG 3350 and 100mM ascorbic acid pD 6.0 (pH 5.6). The crystal was incubated for two hours after which it was flash-frozen in liquid nitrogen using the deuterated buffer supplemented with $25 \%$ glycerol as cryoprotectant. Time-of-flight neutron diffraction data were collected on beamline 11B, the Macromolecular Neutron Diffractometer (MaNDi) at the Spallation Neutron Source (SNS) at Oak Ridge National Laboratory. ${ }^{62}$

\section{Crystal low pH vapor exchange data collection}

To obtain low pH conditions in the LPMO crystal, a large crystal was harvested and mounted in a quartz capillary to which a deuterated low pH buffer was added to facilitate vapor exchange in three stages. $^{63,64}$ The first vapor exchange was performed in 22\% PEG 3350 and 100 mM sodium acetate pD 5.6 (pH 5.2) for three days, followed by $22 \%$ PEG 3350 and $100 \mathrm{mM}$ sodium acetate pD 5.2 (pH 4.8) for six days and 22\% PEG 3350 and 100 mM sodium acetate pD 4.8 (pH 4.4) for 16 days. Time-of-flight neutron diffraction data were collected on beamline 11B, the Macromolecular Neutron Diffractometer (MaNDi) at the Spallation Neutron Source (SNS) at Oak Ridge National Laboratory. ${ }^{62}$ Following this, an X-ray dataset was collected on the same crystal at $298 \mathrm{~K}$ using a copper rotating-anode home source. 


\section{Crystal low pH direct soak and data collection}

LPMO crystals were directly exposed to acidic conditions by soaking crystals in low pH buffer. A crystal was transferred to a buffer composed of 22\% PEG 3350, $100 \mathrm{mM}$ and $100 \mathrm{mM}$ sodium acetate with sequential incubation at $\mathrm{pH} 5.6, \mathrm{pH} 5.2$ and finally $\mathrm{pH} 4.8$ for ten minutes each. Crystals were subsequently flash-frozen in liquid nitrogen with the $\mathrm{pH} 4.8$ acidic buffer supplemented with $25 \%$ glycerol used as a cryoprotectant. Data were collected at $100 \mathrm{~K}$ using a copper rotating-anode home source.

\section{Model refinement}

X-ray data were indexed, integrated and scaled with CrysAlisPRO and the CCP4 suite. ${ }^{65,66}$ Neutron diffraction data were reduced using the Mantid data analysis and visualization package ${ }^{67}$ The time-offlight diffraction data were integrated using three-dimensional profile fitting of the Bragg peaks. ${ }^{68}$ Structure solution and refinement of the X-ray diffraction data of the low $\mathrm{pH}$ structures as well the neutron diffraction data of the ascorbate-soaked structure were performed by utilizing the PHENIX software suite with manual model building to fit density maps performed in Coot. ${ }^{69-71}$ Dioxygen species were modelled using restrained bond length refinements.

\section{Electronic structure (density functional theory) calculations}

The active site models used for DFT calculation were derived by extracting coordinates from the resting state X-ray structure (PDB 5TKG, O’Dell et al. ${ }^{30}$ ) including residues His1, His84, His157, Gln166 and Tyr168 along with the active site copper(II) ion, pre-bound molecular $\mathrm{O} 2$ and the axial and equatorial water molecules. To reduce the total number of atoms in these models, the main chain of residues His84, His157, Gln166 and Tyr168 were truncated at $C_{\beta}$ which was modeled as a methyl group. DFT calculations were performed with Gaussian 09 using the B3LYP functional with the 6-31G** basis set applied to all atoms. The model was implicitly solvated using the polarizable continuum model as implemented in Gaussian 09 with a dielectric constant of 4.24 (scrf keyword solvent=DiethylEther). For geometry optimization, the coordinates of one heavy atom per residue (as performed previously in DFT calculation 
of LPMO9D in $\mathrm{O}^{\prime}$ Dell et $a .^{30}$ ) were constrained to their starting values to maintain the relative conformation imposed by the protein backbone.

\section{MD simulations}

Molecular dynamics (MD) simulations were performed for LMPO in explicit water solvent, using protocol developed in our lab. ${ }^{72}$ Model preparation and simulations were performed using the AMBER v16 suite of programs for biomolecular simulations. ${ }^{73}$ AMBER's ff14SB force-fields were used for all simulations. ${ }^{74} \mathrm{MD}$ simulations were performed using NVIDIA graphical processing units (GPUs) and AMBER's pmemd.cuda simulation engine using our lab protocols published previously. ${ }^{75,76}$

A total of 4 separate simulations were performed for LPMO in the monomeric form. Monomer form was used to avoid crystal packing artifacts. First MD used the structure determined in this study with His157 in the inward conformation, another MD started with His157 in outward conformation obtained from VM2 calculations. The third MD simulation was based on structure with PDB code 5UFW (first protomer only). To rule out difference in results between monomeric and dimeric form, a fourth MD simulation was performed with LPMO in dimeric form based on the structure reported here. (The results of the dimeric complexes were similar to the monomeric form, and were excluded from further analysis.)

The missing hydrogen atoms were added by AMBER's tleap program. After processing the coordinates of the protein and substrate, all systems were neutralized by addition of counter-ions and the resulting system were solvated in a rectangular box of SPC/E water, with a $10 \AA$ minimum distance between the protein and the edge of the periodic box. The prepared systems were equilibrated using a protocol described previously. ${ }^{76}$ To keep $\mathrm{Cu}$ in the active-site for each protomer, 6 distance restraints (5.0 $\mathrm{kcal} / \mathrm{mol} / \mathrm{A}^{2}$ ) were applied between the following atoms: $\mathrm{Cu}-\mathrm{His} 1_{\mathrm{N}}, \mathrm{Cu}-\mathrm{His} 1_{\mathrm{ND} 1}, \mathrm{Cu}-\mathrm{His} 84_{\mathrm{NE1}}, \mathrm{Cu}-168 \mathrm{Tyr}_{\mathrm{OH}}$, and $\mathrm{Cu}$ with the two crystallographic water oxygen atoms. For 5 UFW based system: $\mathrm{Cu}-\mathrm{His} 1_{\mathrm{N}}, \mathrm{Cu}-\mathrm{His} 1_{\mathrm{ND} 1}$, $\mathrm{Cu}-\mathrm{His} 75_{\mathrm{NE} 1}, \mathrm{Cu}-169 \mathrm{Tyr}_{\mathrm{OH}}$, and $\mathrm{Cu}$ with the two crystallographic water oxygen atoms. 
The equilibrated systems were then used to run $1.0 \mu$ s of production MD under constant energy conditions (NVE ensemble) and the 6 distance restraints per protomer. The use of NVE ensemble is preferred as it offers better computational stability and performance. ${ }^{77}$ The production simulations were performed at a temperature of $300 \mathrm{~K}$. As NVE ensemble was used for production runs, these values correspond to initial temperature at start of simulations. Temperature adjusting thermostat was not used in simulations; over the course of $1.0 \mu$ s simulations the temperature fluctuated around $300 \mathrm{~K}$ with RMS fluctuations between 2-4 K, which is typical for well equilibrated systems. A total of 1,000 conformational snapshots (stored every 1,000 ps) collected for each system was used for analysis. Structures were visualized using PyMOL.

\section{VM2 calculations}

VM2 is an implementation of the second-generation Mining Minima (M2) method originally developed by Gilson et al. ${ }^{78-83}$ It is a free energy calculation method, which combines extensive molecular conformational searching ${ }^{53,84}$ with a rigorous statistical mechanics approach. ${ }^{78}$ Molecular configuration

integrals over all space are closely approximated in a tractable manner by summation of local configuration integrals associated with the low energy minima of the system. ${ }^{85,86} \mathrm{VM} 2$ 's search algorithm can drive molecular conformations over high-energy barriers, via a mode-distort-minimize procedure, to find relevant minima even when they structurally diverse. As such, VM2 is well suited for exploration of thermally accessible conformations of His157 in monomeric and dimeric NcLPMO9D, respectively, as carried out in this study.

We applied molecular mechanics (MM) based VM2, taking the AMBER ff14SB parameter files (prmtop etc.) generated by the setup for MD simulations (see above) and converting them to formats readable by the VM2 software. It should be noted that for computational efficiency, VM2 includes solvation effects through continuum models (see below for details), so only the water molecules coordinating directly with active site copper centers were explicitly included. To further manage 
computational expense, and to focus on the region of interest, not all protein atoms were included in the VM2 calculation. Rather, a "cutout" approach was taken, where all residues containing an atom within 14 $\AA$ of the His157 alpha carbon (CA) were present in the energy model, and of these all atoms within $12 \AA$ of His157 CA were set as mobile. For the monomer, this resulted in 904 atoms present in the calculation, with 476 of these mobile; for the dimer, this resulted in 1256 atoms present, with 600 of these mobile. To maintain the basic arrangement of the active site copper first-shell coordination residues (histidine brace, tyrosine, and two water molecules) during aggressive conformational searching, a flat-bottomed energy well restraint potential1 was applied to their coordinating atoms, as well as the central copper atom itself.

VM2 is an iterative method, ${ }^{53}$ with each iteration comprising a conformational search, with removal of any repeat conformers produced, calculation of the configuration integrals at $300 \mathrm{~K}$ for the resulting set of new conformers, ${ }^{85,86}$ addition of this set of conformers to the pool already established, and then determination of the total free energy by summation of the local configuration integrals of all conformers (minima) currently in the pool. Once the conformational search no longer finds new low energy conformers the total free energy stops changing between iterations. The calculations in this study were deemed converged when the absolute value of the free energy change between iterations was less than $0.01 \mathrm{kcal} \mathrm{mol}^{-1}$. The conformational search carried out during each VM2 iteration included 1200 mode-distort-minimize procedures. Molecular distortions were from atom displacements along singlemodes produced by diagonalization of the Hessian matrix in torsional space and, in addition, atom displacements based on random combinations of pairs of these modes. ${ }^{53,84}$ For energy-derivative involved steps, e.g. the mode-distort-minimize procedure and the Hessian (energy 2nd-derivative) calculation, required for configurational entropy terms, solvation energy was included using the generalized Born (GB) continuum model..$^{87,88}$ The Poisson-Boltzmann Surface Area (PBSA) method ${ }^{89}$ was applied to provide a more accurate single-point solvation energy correction at GB determined geometries. On completion, VM2 calculations output the total free energy, and in addition the relative free energy of each individual 
conformer along with its Boltzmann distribution probability. Also outputted are PDB and mol2 formatted files containing all protein conformers produced within $10 \mathrm{kcal} \mathrm{mol}^{-1}$ of the lowest energy conformer, up to a maximum of 1,000 , allowing for structural visualization and analysis. 


\section{Conflicts of interest}

SPW declares an equity interest in VeraChem LLC, which develops the VM2 free energy software package. The remaining authors declare no conflict of interest.

\section{Acknowledgements}

Protein expression, purification and crystallization experiments were conducted at the Center for Structural Molecular Biology (CSMB), a U.S. Department of Energy Biological and Environmental Research User Facility at Oak Ridge National Laboratory. Neutron diffraction data was collected at BL-11B MaNDi at the Spallation Neutron Source (SNS) at ORNL which is sponsored by the Scientific User Facilities Division, Office of Basic Energy Sciences, U.S. Department of Energy. The authors thank Brendan Sullivan for assistance with data reduction. X-ray diffraction data was collected at the Molecular Education, Technology, and Research Innovation Center (METRIC) facilities at North Carolina State University, which is supported by the State of North Carolina. GCS acknowledges support in part from the National Research Foundation (NRF), South Africa and the Oak Ridge National Laboratory Graduate Opportunities (GO!) program. FM acknowledges support from USDA NIFA Hatch 211001. 


\section{References}

1 K. K. Meier, S. M. Jones, T. Kaper, H. Hansson, M. J. Koetsier, S. Karkehabadi, E. I. Solomon, M. Sandgren and B. Kelemen, Chem. Rev., 2018, 118, 2593-2635.

2 R. J. Quinlan, M. D. Sweeney, L. Lo Leggio, H. Otten, J. C. N. Poulsen, K. S. Johansen, K. B. R. M. Krogh, C. I. Jørgensen, M. Tovborg, A. Anthonsen, T. Tryfona, C. P. Walter, P. Dupree, F. Xu, G. J. Davies and P. H. Walton, Proc. Natl. Acad. Sci. U. S. A., 2011, 108, 15079-15084.

3 C. M. Phillips, W. T. Beeson, J. H. Cate and M. A. Marletta, ACS Chem. Biol., 2011, 6, 1399-1406.

4 W. T. Beeson, C. M. Phillips, J. H. D. Cate and M. A. Marletta, J. Am. Chem. Soc., 2012, 134, 890892.

5 W. T. Beeson, V. V. Vu, E. A. Span, C. M. Phillips and M. A. Marletta, Annu. Rev. Biochem., 2015, 84, 923-946.

6 B. Bissaro, Å. K. Røhr, G. Müller, P. Chylenski, M. Skaugen, Z. Forsberg, S. J. Horn, G. Vaaje-Kolstad and V. G. H. Eijsink, Nat. Chem. Biol., 2017, 13, 1123-1128.

7 X. Li, W. T. Beeson, C. M. Phillips, M. A. Marletta and J. H. D. Cate, Structure, 2012, 20, 1051-1061.

8 C. H. Kjaergaard, M. F. Qayyum, S. D. Wong, F. Xu, G. R. Hemsworth, D. J. Walton, N. A. Young, G. J. Davies, P. H. Walton, K. S. Johansen, K. O. Hodgson, B. Hedman and E. I. Solomon, Proc. Natl. Acad. Sci., 2014, 111, 8797-8802.

9 J. A. Hangasky, T. C. Detomasi and M. A. Marletta, Trends Chem., 2019, 1, 198-209.

10 P. Chylenski, B. Bissaro, M. Sørlie, Å. K. Røhr, A. Várnai, S. J. Horn and V. G. H. Eijsink, ACS Catal., 2019, 9, 4970-4991.

11 R. L. Peterson, R. A. Himes, H. Kotani, T. Suenobu, L. Tian, M. A. Siegler, E. I. Solomon, S. Fukuzumi and K. D. Karlin, J. Am. Chem. Soc., 2011, 133, 1702-1705.

12 S. I. Mann, T. Heinisch, T. R. Ward and A. S. Borovik, J. Am. Chem. Soc., 2017, 139, 17289-17292.

13 R. Trammell, Y. Y. See, A. T. Herrmann, N. Xie, D. E. Díaz, M. A. Siegler, P. S. Baran and I. GarciaBosch, J. Org. Chem., 2017, 82, 7887-7904.

14 I. Garcia-Bosch and M. A. Siegler, Angew. Chemie Int. Ed., 2016, 55, 12873-12876.

15 P. J. Donoghue, J. Tehranchi, C. J. Cramer, R. Sarangi, E. I. Solomon and W. B. Tolman, J. Am. Chem. Soc., 2011, 133, 17602-17605.

16 D. Dhar, G. M. Yee, A. D. Spaeth, D. W. Boyce, H. Zhang, B. Dereli, C. J. Cramer and W. B. Tolman, J. Am. Chem. Soc., 2016, 138, 356-368.

D. Schröder, M. C. Holthausen and H. Schwarz, J. Phys. Chem. B, 2004, 108, 14407-14416.

K. Yoshizawa, N. Kihara, T. Kamachi and Y. Shiota, Inorg. Chem., 2006, 45, 3034-3041.

N. Dietl, C. Van Der Linde, M. Schlangen, M. K. Beyer and H. Schwarz, Angew. Chemie - Int. Ed., 2011, 50, 4966-4969.

20 S. Kim, J. Ståhlberg, M. Sandgren, R. S. Paton and G. T. Beckham, Proc. Natl. Acad. Sci. U. S. A., 2014, 111, 149-154.

21 E. D. Hedegård and U. Ryde, J. Biol. Inorg. Chem., 2017, 22, 1029-1037.

E. D. Hedegård and U. Ryde, Chem. Sci., 2018, 9, 3866-3880.

L. Bertini, R. Breglia, M. Lambrughi, P. Fantucci, L. De Gioia, M. Borsari, M. Sola, C. A. Bortolotti and M. Bruschi, Inorg. Chem., 2018, 57, 86-97.

24 E. A. Span, D. L. M. Suess, M. C. Deller, R. D. Britt and M. A. Marletta, ACS Chem. Biol., 2017, 12, 1095-1103.

O. Caldararu, E. Oksanen, U. Ryde and E. D. Hedegård, Chem. Sci., 2019, 10, 576-586.

28 W. B. O’Dell, A. M. Bodenheimer and F. Meilleur, Arch. Biochem. Biophys., 2016, 602, 48-60. 
G. C. Schröder and F. Meilleur, Acta Crystallogr. Sect. D Struct. Biol., 2021, 77, 1251-1269. W. B. O'Dell, P. K. Agarwal and F. Meilleur, Angew. Chemie - Int. Ed., 2017, 56, 767-770. W. B. O’Dell, P. D. Swartz, K. L. Weiss and F. Meilleur, Acta Crystallogr. Sect. Struct. Biol. Commun., 2017, 73, 70-78.

32 S. Karkehabadi, H. Hansson, S. Kim, K. Piens, C. Mitchinson and M. Sandgren, J. Mol. Biol., 2008, 383, 144-154.

33 P. V. Harris, D. Welner, K. C. McFarland, E. Re, J. C. Navarro Poulsen, K. Brown, R. Salbo, H. Ding, E. Vlasenko, S. Merino, F. Xu, J. Cherry, S. Larsen and L. Lo Leggio, Biochemistry, 2010, 49, 3305-3316. M. Eibinger, J. Sattelkow, T. Ganner, H. Plank and B. Nidetzky, Nat. Commun., 2017, 8, 894. K. E. H. Frandsen, T. J. Simmons, P. Dupree, J. C. N. Poulsen, G. R. Hemsworth, L. Ciano, E. M. Johnston, M. Tovborg, K. S. Johansen, P. Von Freiesleben, L. Marmuse, S. Fort, S. Cottaz, H. Driguez, B. Henrissat, N. Lenfant, F. Tuna, A. Baldansuren, G. J. Davies, L. Lo Leggio and P. H. Walton, Nat. Chem. Biol., 2016, 12, 298-303.

36 J. P. Bacik, S. Mekasha, Z. Forsberg, A. Y. Kovalevsky, G. Vaaje-Kolstad, V. G. H. Eijsink, J. C. Nix, L. Coates, M. J. Cuneo, C. J. Unkefer and J. C. H. Chen, Biochemistry, 2017, 56, 2529-2532.

37 T. Isaksen, B. Westereng, F. L. Aachmann, J. W. Agger, D. Kracher, R. Kittl, R. Ludwig, D. Haltrich, V. G. H. Eijsink and S. J. Horn, J. Biol. Chem., 2014, 289, 2632-2642.

M. Gudmundsson, S. Kim, M. Wu, T. Ishida, M. H. Momeni, G. Vaaje-Kolstad, D. Lundberg, A. Royant, J. Ståhlberg, V. G. H. Eijsink, G. T. Beckham and M. Sandgren, J. Biol. Chem., 2014, 289, 18782-18792.

39 B. D. Neisen, N. L. Gagnon, D. Dhar, A. D. Spaeth and W. B. Tolman, J. Am. Chem. Soc., 2017, 139, 10220-10223.

40 B. Kim, D. Jeong, T. Ohta and J. Cho, Commun. Chem., 2019, 2, 1-6.

41 B. Westereng, D. Cannella, J. Wittrup Agger, H. Jørgensen, M. Larsen Andersen, V. G. H. Eijsink and C. Felby, Sci. Rep., 2015, 5, 1-9.

42 G. Courtade, R. Wimmer, Å. K. Røhr, M. Preims, A. K. G. Felice, M. Dimarogona, G. Vaaje-Kolstad, M. Sørlie, M. Sandgren, R. Ludwig, V. G. H. Eijsink and F. L. Aachmann, Proc. Natl. Acad. Sci. U. S. A., 2016, 113, 5922-5927.

43 L. Ciano, G. J. Davies, W. B. Tolman and P. H. Walton, Nat. Catal., 2018, 1, 571-577.

44 D. Dhar and W. B. Tolman, J. Am. Chem. Soc., 2015, 137, 1322-1329.

45 A. Paradisi, E. M. Johnston, M. Tovborg, C. Nicoll, L. Ciano, A. Dowle, J. McMaster, Y. Hancock, G. J. Davies and P. H. Walton, J. Am. Chem. Soc., 2019, jacs.9b09833.

46 R. K. Singh, B. M. Blossom, D. A. Russo, R. Singh, H. Weihe, N. H. Andersen, M. K. Tiwari, P. E. Jensen, C. Felby and M. J. Bjerrum, Chem. - A Eur. J., 2020, 26, 454-463.

47 A. Mcevoy, J. Creutzberg, R. K. Singh, M. J. Bjerrum and E. D. Hedegård, Chem. Sci., 2021, 12, 352362.

48 M. Schülein, J. Biotechnol., 1997, 57, 71-81.

H. Boer and A. Koivula, Eur. J. Biochem., 2003, 270, 841-848.

50 S. M. Cragg, G. T. Beckham, N. C. Bruce, T. D. H. Bugg, D. L. Distel, P. Dupree, A. G. Etxabe, B. S. Goodell, J. Jellison, J. E. McGeehan, S. J. McQueen-Mason, K. Schnorr, P. H. Walton, J. E. M. Watts and M. Zimmer, Curr. Opin. Chem. Biol., 2015, 29, 108-119.

51 K. E. H. Frandsen, J. C. N. Poulsen, T. Tandrup and L. Lo Leggio, Carbohydr. Res., 2017, 448, 187190.

52 A. Ramanathan, A. Savol, V. Burger, C. S. Chennubhotla and P. K. Agarwal, Acc. Chem. Res., 2014, 47, 149-156.

53 W. Chen, M. K. Gilson, S. P. Webb and M. J. Potter, J. Chem. Theory Comput., 2010, 6, 3540-3557.

54 Y. M. M. Huang, W. Chen, M. J. Potter and C. E. A. Chang, Biophys. J., 2012, 103, 342-351.

55 W. You, Y. ming M. Huang, S. Kizhake, A. Natarajan and C. en A. Chang, PLoS Comput. Biol., 2016, 
$12,1-25$.

56 P. Xu, T. Sattasathuchana, E. Guidez, S. P. Webb, K. Montgomery, H. Yasini, I. F. M. Pedreira and M.

S. Gordon, J. Chem. Phys., , DOI:10.1063/5.0040759.

57 P. J. Lodi and J. R. Knowles, Biochemistry, 1991, 30, 6948-6956.

58 C. Lennartz, A. Schäfer, F. Terstegen and W. Thiel, J. Phys. Chem. B, 2002, 106, 1758-1767.

59 G. T. Marks, M. Susler and D. H. T. Harrison, Biochemistry, 2004, 43, 3802-3813.

60 G. C. Schröder, W. B. O’Dell, P. D. Swartz and F. Meilleur, Acta Crystallogr. Sect. F Struct. Biol. Commun., 2021, 77, 128-133.

61 F. Meilleur, A. Kovalevsky and D. A. A. Myles, in Methods in enzymology, Elsevier Inc., 1st edn., 2020, vol. 634, pp. 69-85.

62 L. Coates, A. D. Stoica, C. Hoffmann, J. Richards and R. Cooper, J. Appl. Crystallogr., 2010, 43, 570577.

63 Q. Wan, J. M. Parks, B. L. Hanson, S. Z. Fisher, A. Ostermann, T. E. Schrader, D. E. Graham, L. Coates, P. Langan and A. Kovalevsky, Proc. Natl. Acad. Sci., 2015, 112, 12384-12389.

64 O. Gerlits, T. Wymore, A. Das, C. H. Shen, J. M. Parks, J. C. Smith, K. L. Weiss, D. A. Keen, M. P. Blakeley, J. M. Louis, P. Langan, I. T. Weber and A. Kovalevsky, Angew. Chemie - Int. Ed., 2016, 55, $4924-4927$.

65 C. P. Kubicek, Fungi and Lignocellulosic Biomass, Wiley-Blackwell, Oxford, UK, 2012.

66 M. D. Winn, C. C. Ballard, K. D. Cowtan, E. J. Dodson, P. Emsley, P. R. Evans, R. M. Keegan, E. B. Krissinel, A. G. W. Leslie, A. McCoy, S. J. McNicholas, G. N. Murshudov, N. S. Pannu, E. A. Potterton, H. R. Powell, R. J. Read, A. Vagin and K. S. Wilson, Acta Crystallogr. Sect. D Biol. Crystallogr., 2011, 67, 235-242.

67 O. Arnold, J. C. Bilheux, J. M. Borreguero, A. Buts, S. I. Campbell, L. Chapon, M. Doucet, N. Draper, R. Ferraz Leal, M. A. Gigg, V. E. Lynch, A. Markvardsen, D. J. Mikkelson, R. L. Mikkelson, R. Miller, K. Palmen, P. Parker, G. Passos, T. G. Perring, P. F. Peterson, S. Ren, M. A. Reuter, A. T. Savici, J. W. Taylor, R. J. Taylor, R. Tolchenov, W. Zhou and J. Zikovsky, Nucl. Instruments Methods Phys. Res. Sect. A Accel. Spectrometers, Detect. Assoc. Equip., 2014, 764, 156-166.

68 B. Sullivan, R. Archibald, P. S. Langan, H. Dobbek, M. Bommer, R. L. McFeeters, L. Coates, X. Wang, F. Gallmeier, J. M. Carpenter, V. Lynch and P. Langan, Acta Crystallogr. Sect. D Struct. Biol., 2018, 74, 1085-1095.

69 P. D. Adams, P. V. Afonine, G. Bunkóczi, V. B. Chen, I. W. Davis, N. Echols, J. J. Headd, L.-W. Hung, G. J. Kapral, R. W. Grosse-Kunstleve, A. J. McCoy, N. W. Moriarty, R. Oeffner, R. J. Read, D. C. Richardson, J. S. Richardson, T. C. Terwilliger and P. H. Zwart, Acta Crystallogr. Sect. D Biol. Crystallogr., 2010, 66, 213-221.

70 P. Emsley, B. Lohkamp, W. G. Scott and K. Cowtan, Acta Crystallogr. Sect. D Biol. Crystallogr., 2010, 66, 486-501.

71 P. V. Afonine, R. W. Grosse-Kunstleve, N. Echols, J. J. Headd, N. W. Moriarty, M. Mustyakimov, T. C. Terwilliger, A. Urzhumtsev, P. H. Zwart and P. D. Adams, Acta Crystallogr. Sect. D Biol. Crystallogr., 2012, 68, 352-367.

72 C. Narayanan, D. N. Bernard, K. Bafna, D. Gagné, C. S. Chennubhotla, N. Doucet and P. K. Agarwal, Structure, 2018, 26, 426-436.e3.

73 D. A. Case, J. T. Berryman, R. M. Betz, D. S. Cerutti, T. E. Cheatham, T. A. Darden, R. E. Duke, T. J. Giese, H. Gohlke, A. W. Goetz, N. Homeyer, S. Izadi, P. Janowski, J. Kaus, A. Kovalenko, T. S. Lee, S. LeGrand, P. Li, T. Luchko, R. Luo, B. Madej, K. M. Merz, G. Monard, P. Needham, H. Nguyen, H. T. Nguyen, I. Omelyan, A. Onufriev, D. R. Roe, A. Roitberg, R. Salomon-Ferrer, C. L. Simmerling, W. Smith, J. Swails, R. C. Walker, J. Wang, R. M. Wolf, X. Wu, D. M. York and P. A. Kollman, AMBER 15, University of California, San Francisco, 2015.

74 J. A. Maier, C. Martinez, K. Kasavajhala, L. Wickstrom, K. E. Hauser and C. Simmerling, J. Chem. 
Theory Comput., 2015, 11, 3696-3713.

75 A. Ramanathan, P. K. Agarwal, M. Kurnikova and C. J. Langmead, J. Comput. Biol., 2010, 17, 309324.

76 M. R. Duff, J. M. Borreguero, M. J. Cuneo, A. Ramanathan, J. He, G. Kamath, S. C. Chennubhotla, F. Meilleur, E. E. Howell, K. W. Herwig, D. A. A. Myles and P. K. Agarwal, Biochemistry, 2018, 57, 42634275.

77 S. Shukla, K. Bafna, C. Gullett, D. A. A. Myles, P. K. Agarwal and M. J. Cuneo, Biochemistry, 2018, 57, 5864-5876.

78 M. K. Gilson, J. A. Given, B. L. Bush and J. A. McCammon, Biophys. J., 1997, 72, 1047-1069.

79 M. S. Head, J. A. Given and M. K. Gilson, J. Phys. Chem. A, 1997, 101, 1609-1618.

80 L. David, R. Luo and M. K. Gilson, J. Comput. Aided. Mol. Des., 2001, 15, 157-71.

81 V. Kairys and M. K. Gilson, J. Comput. Chem., 2002, 23, 1656-1670.

82 C. E. Chang and M. K. Gilson, J. Am. Chem. Soc., 2004, 126, 13156-13164.

83 W. Chen, C. E. Chang and M. K. Gilson, Biophys. J., 2004, 87, 3035-3049.

84 C. E. Chang and M. K. Gilson, J. Comput. Chem., 2003, 24, 1987-1998.

85 C. E. Chang, M. J. Potter and M. K. Gilson, J. Phys. Chem. B, 2003, 107, 1048-1055.

86 M. J. Potter and M. K. Gilson, J. Phys. Chem. A, 2002, 106, 563-566.

87 D. Qiu, P. S. Shenkin, F. P. Hollinger and W. C. Still, J. Phys. Chem. A, 1997, 101, 3005-3014.

88 W. C. Still, A. Tempczyk, R. C. Hawley and T. Hendrickson, J. Am. Chem. Soc., 1990, 112, 6127-6129.

89 R. Luo, L. David and M. K. Gilson, J. Comput. Chem., 2002, 23, 1244-1253. 